Portland State University

PDXScholar

$12-16-2019$

\title{
A Mixed Methods Analysis of Corpus Data from Reddit Discussions of "Gay Voice"
}

Sara Elizabeth Mulliner

Portland State University

Follow this and additional works at: https://pdxscholar.library.pdx.edu/open_access_etds

Part of the Anthropological Linguistics and Sociolinguistics Commons, Discourse and Text Linguistics Commons, and the Lesbian, Gay, Bisexual, and Transgender Studies Commons Let us know how access to this document benefits you.

\section{Recommended Citation}

Mulliner, Sara Elizabeth, "A Mixed Methods Analysis of Corpus Data from Reddit Discussions of "Gay Voice"'" (2019). Dissertations and Theses. Paper 5443.

https://doi.org/10.15760/etd.7316

This Thesis is brought to you for free and open access. It has been accepted for inclusion in Dissertations and Theses by an authorized administrator of PDXScholar. Please contact us if we can make this document more accessible: pdxscholar@pdx.edu. 
A Mixed Methods Analysis of Corpus Data from Reddit Discussions of "Gay Voice"

by

Sara Elizabeth Mulliner

A thesis submitted in partial fulfillment of the requirements for the degree of

Master of Arts

in

Teaching English to Speakers of Other Languages

Thesis Committee:

John Hellermann, Chair

Lynn Santelmann

Steven L.Thorne

Portland State University

2019 
(C) 2019 Sara Elizabeth Mulliner 


\begin{abstract}
In the last decade, there have been a number of public discussions about "gay voice" and "sounding gay." These two phrases often serve as a shorthand for the belief that a listener can determine the sexuality of a speaker based on phonetic qualities found in a speaker's vocal output. However, these expressions are more accurately described as "catch-all" terms for speech that may contain features associated with non-gender conforming stances and personae (Zimman, 2013). Notions about gender and sexuality could be intertwined in complicated ways in this language ideology. Investigating popular discussions of gay-sounding voices could provide information on what people are trying to convey when they use this phrase and the relationship between social categorization and language-based stereotypes.

This study examines discourses surrounding the phrases "gay voice" and "sound/sounds/sounded/sounding gay" (i.e. "sound* gay") in conversations found on the popular U.S.-based online forum Reddit. A statistical technique known as topic modeling is used to identify salient topics from a corpus of text to meaningfully sample a subset of online discussions for discourse analysis. I perform this research to understand the ways in which discourses about gender and sexuality constitute what it means to sound gay. The study found that there are two main reasons that Reddit users discuss "sounding gay": (1) to gain insights about its origin and cross-linguistic occurrence, and (2) to discuss the sociosexual capital of having a "gay voice" and ways to change one's own voice to conform more closely with normative ideals. Conversations revolving around the first theme are found in subforums for a general audience, while dialogues about the
\end{abstract}


second theme occur in LGBTQ+-related subforums (i.e. askgaybros, ftm). Discussions across both topics tend to rely on a gender inversion theory of non-normative sexualities, even as some users seek to denaturalize the idea that a person can have a "gay voice." These findings suggest that essentialist ideas about gender and sexuality inform what it means to "sound gay." 


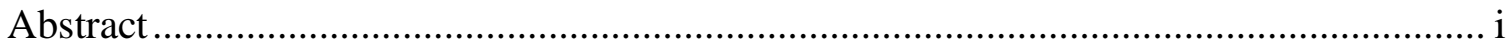

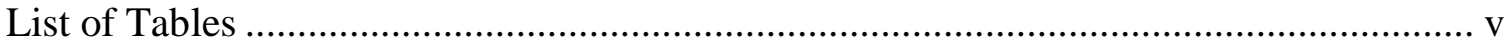

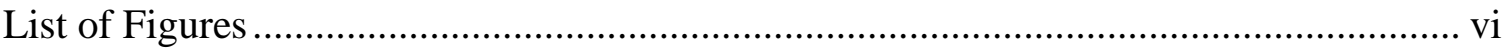

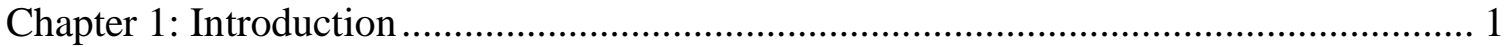

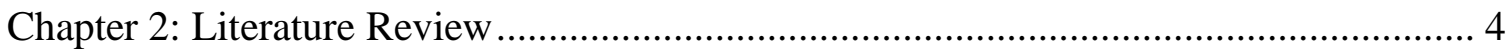

2.1 Linguistic Investigations of Gay-Sounding Voices ........................................... 4

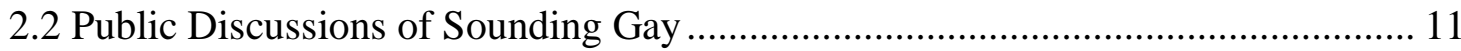

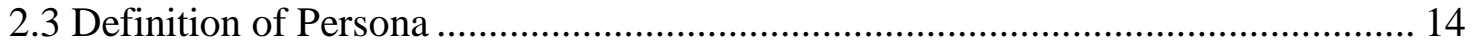

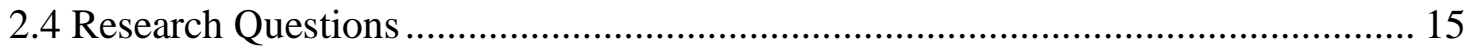

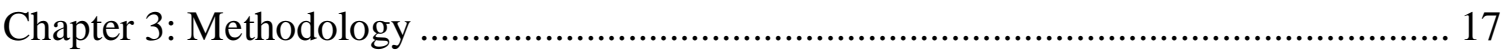

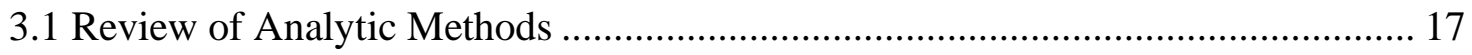

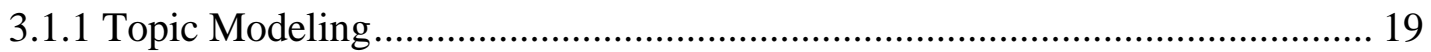

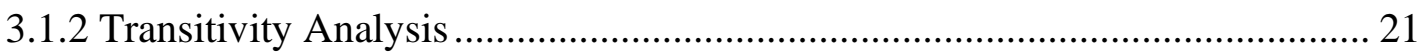

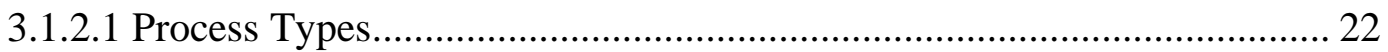

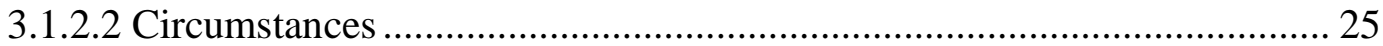

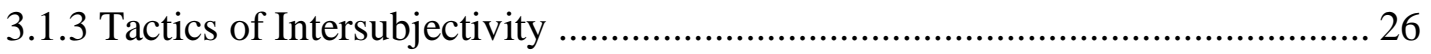

3.1.3.1 Concept: Markedness ...................................................................... 28

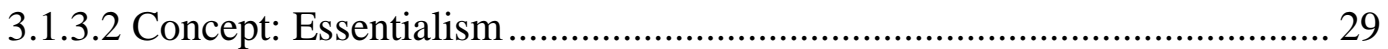

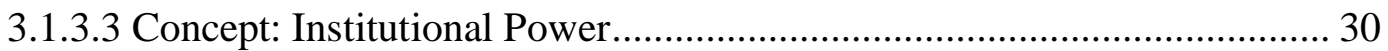

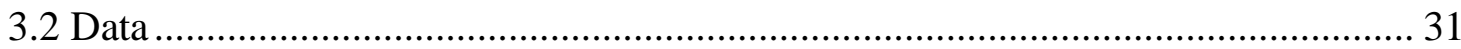

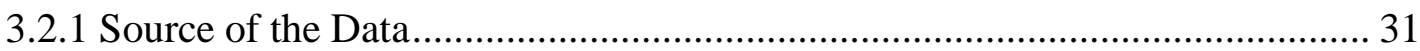

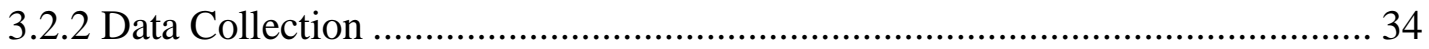

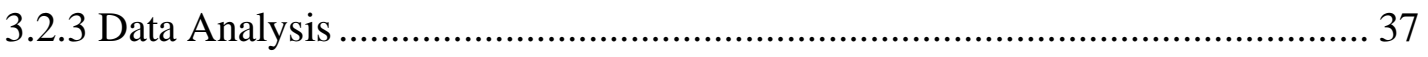

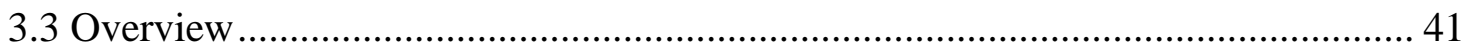

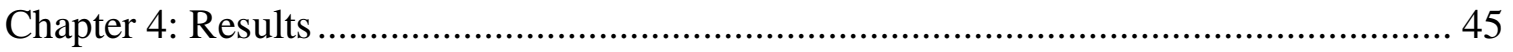

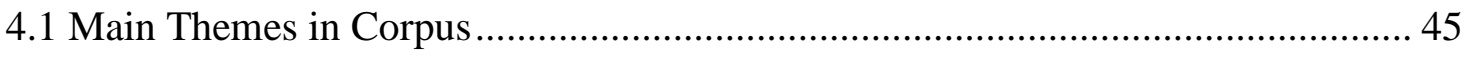

4.2 Context for the Discourse Analysis ............................................................. 53

4.2.1 What acoustic features do Reddit users in these excerpts associate with a "gay-

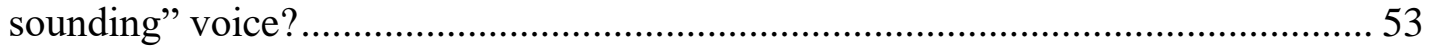

4.2.2 Which subreddits are these excerpts found on? ...................................... 54

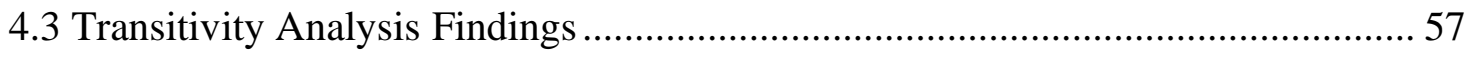




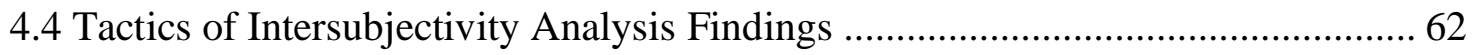

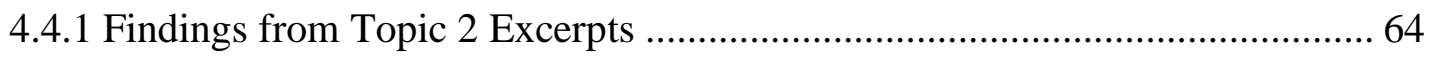

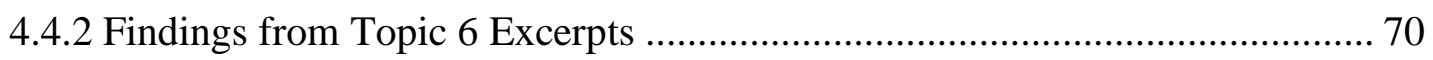

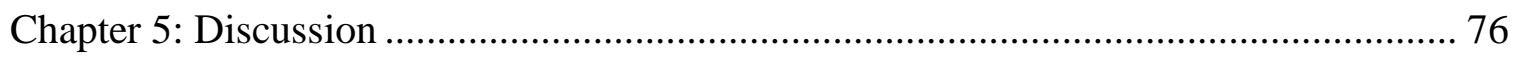

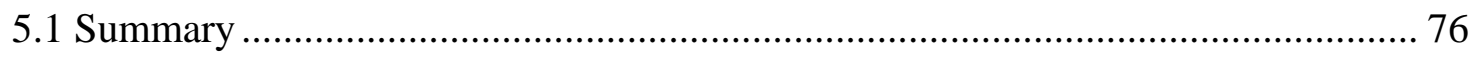

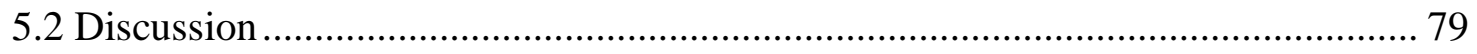

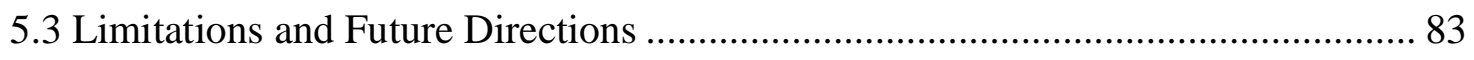

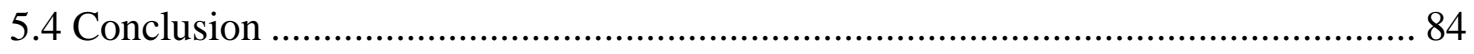

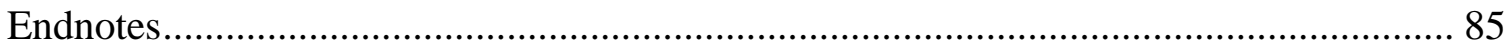

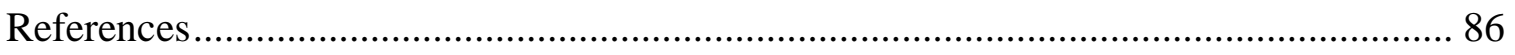

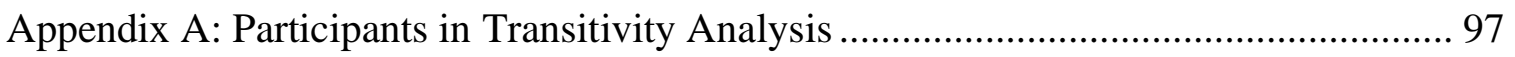

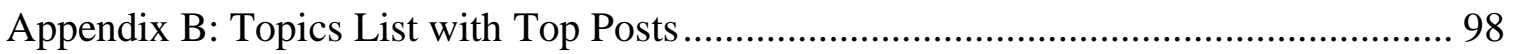

Appendix C: Excerpts from Topic 2 and Topic 6 Posts ............................................ 101

Appendix D: Subreddits Represented in Corpus ................................................. 115 


\section{List of Tables}

Table 3.1: Circumstances in Transitivity Analysis .................................................. 26

Table 3.2: Bucholtz and Hall's Tactics of Intersubjectivity ....................................... 28

Table 3.3: Topics List for 'gay voice' and 'sound* gay' across 76 Reddit Posts ............ 39

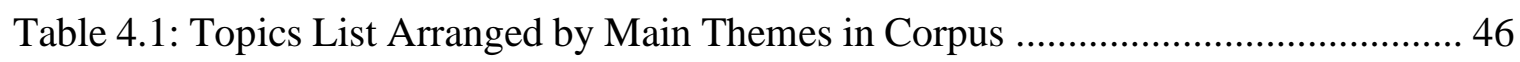

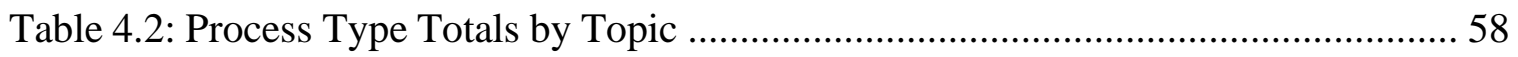




\section{List of Figures}

Figure 3.1: The semantic field of process types in transitivity analysis ........................ 25

Figure 3.2: A visual glossary of terms that are used frequently in this thesis ....................... 44

Figure 4.1: An example of interaction that represents Theme 5 ................................ 52

Figure 4.2: A visual summary of the tactics of intersubjectivity analysis findings ........ 64

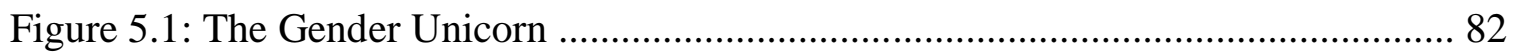




\section{Chapter 1: Introduction}

Sitting in my living room the summer before I started grad school, my friend shared with me that he was dating a new person, and I had asked him to list off some things that he liked about him. As part of this list, he noted: “. . . and he has a straightpassing voice, which is really important in case we want to travel ..." The implication: that there is a voice that does not, cannot, pass for straight, and that this voice puts people at risk depending on the situation they find themselves in. This comment stuck with me. I was familiar with the notion that a person's sexuality could be inferred from their speech but hearing my friend talk about it in this way gave it an immediacy that I had not felt about it before. As a student of linguistics, I felt like I needed more insight into this notion and its impact.

This conversation with my friend took place at a time when the idea of "sounding gay" was being talked about in the media. For example, the documentary Do I Sound Gay? (Thorpe \& Gertler, 2014) led to a number of discussions in the press related to the notion of "gay-sounding" speech. For years before that, "gay voice" had been used by performers (particularly comedians) as a way to be legible as gay characters. Even linguists had been conducting investigations into what it means to "sound gay" since the mid-1990s, but had failed to find evidence for a unitary set of features characteristic of gay-sounding voices.

In my second year of graduate studies, I took a course on Language, Gender, \& Sexuality and found that multiple scholars had noted that the label "gay" is often used as 
a comment on a person's gender normativity rather than their sexual practices. For example, in an article about how heterosexuality is constructed in language, Cameron (1997) describes a moment in her participant's talk where they refer to a male classmate as homosexual right before characterizing him as dating ugly women. From this comment she argues that sometimes calling someone out as gay is less about perceived "sexual deviance" than "gender deviance" — the label gets extrapolated to people who do not measure up to one's standards of gender performance (p. 331). Zimman (2013) made an almost identical point: “Gayness . . . can serve as a catch-all category for stigmatized forms of male gender expression" (p. 10). The points raised by these scholars led me to ask: what does this conflation of gender and sexuality have to do with the idea that a person can sound gay?

The phrase "gay voice" often serves as a shorthand for the belief that a listener can determine the sexuality of a speaker based on phonetic qualities found in their speech. However, it is more accurately described as a "catch-all" term for speech that contains phonetic features associated with non-gender conforming stances and personae (Zimman, 2013). This paper analyzes discourses surrounding the expressions "gay voice" and "sound/sounds/sounded/sounding gay" (i.e. "sound* gay") in discussions found on the popular U.S.-based online forum platform Reddit. I use a statistical technique that identifies salient themes from a corpus of text to meaningfully sample a subset of online discussions for discourse analysis. I perform this research to understand the ways in which discourses about gender and sexuality constitute what it means to sound gay. Investigating popular discussions of gay-sounding voices could provide information on 
what people are trying to convey when they use this phrase and the relationship between social categorization and language-based stereotypes. 


\section{Chapter 2: Literature Review}

In this chapter, I begin by reviewing previous literature on gay-sounding voices. Next, I describe a series of events in the media in which sounding gay was discussed. I proceed to define the term "persona," a key concept for the analysis that follows. I conclude with a description of the research questions that guide the study.

\subsection{Linguistic Investigations of Gay-Sounding Voices}

There exists “a widespread stereotype about gay men . . . that they sound gay,' i.e. their pitch and intonational patterns broadcast their homosexuality, whether they like it or not" (Kulick, 2000, p. 260). A number of scholars since the mid-1990s have investigated this "common intuition" (Levon, 2007, p. 533) that the sexual orientation of a speaker who is (perceived to be) male can be determined by listening to his speech; Gaudio, 1994; Mack \& Munson, 2012; Munson, 2007). Studies that have directly tested the hypothesis, however, have not adduced evidence that supports this belief. For example, Smyth, Jacobs, and Rogers (2003) 'reported a 'gaydar' accuracy rate of only about 57\% for a sample of 46 listeners, despite the fact that they exhibited a good deal of agreement about which voices sounded gay" (as cited in Smyth \& Rogers, 2008, p. 129). Four widely-cited studies in this area further demonstrate that linguistic inquiry into the matter cannot support the notion of a monolithic "gay voice": Gaudio (1994), Munson, McDonald, DeBoe, and White (2006), Podesva (2007), and Zimman (2013). 
Gaudio (1994) approached the question of which features are associated with gay male speech by collecting data on perceived sexuality of sample voices and comparing these ratings to objective acoustic measures of pitch range and variability. Eight male university students (4 straight, 4 gay) were recorded reading two short passages: one an accounting text, the other a short passage from a dramatic piece. The researcher then played these sound clips to 13 undergraduates who were asked to rate the speaker they heard in each condition on a Likert scale of 1-7 based on the Osgood semantic differential (e.g. gay-straight, reserved-emotional). He found that although a significant difference in pitch range was present between straight and gay speakers for the accounting text, no other significant acoustic differences were found between recordings. Despite this, listeners were able to correctly identify the sexual orientation of the speaker over $90 \%$ of the time. Aside from the small sample size, this finding "can only be accounted for by assuming that listeners' evaluations were based on criteria other than intonation alone” (Kulick, 2000, p. 261). Moreover, Gaudio (1994) notes that “ . . the fact that listeners fairly consistently judged speech as sounding either 'gay' and 'effeminate' or 'straight' and 'masculine' points to a need for sociolinguists to investigate the cultural sources of these judgements" (p. 54). This experiment laid the groundwork for later scholars investigating the relationship between perception and production in the study of what it means to sound gay.

In an investigation of the speech of both men and women, Munson, McDonald, DeBoe, and White (2006) collected speech samples from 44 adults (11 gay men, 11 heterosexual men, 11 lesbian/bisexual women, and 11 heterosexual women). The 
researchers recorded the participants reading word lists that varied based on whether the token had a front or back vowel and the presence or absence of a sibilant fricative, and then analyzed the acoustic differences between speakers. They found that "gay men produced a higher F1 frequency in /æa and /E/ and a more negatively skewed /s/ spectrum (i.e. the concentration of acoustic energy was found in the frequencies above the mean)" when compared to straight men (Munson, 2007, p. 127). They also conducted a perceptual experiment in which 40 listeners were asked to rate what they perceived the speaker's sexual orientation to be based on a five-point Likert scale, i.e. "where 1 indicated definitely sounds heterosexual, 3 indicated sounds neither heterosexual nor gay/lesbian/bisexual (GLB) and 5 indicated definitely sounds GLB" (Munson et al., 2006, p. 218). F1 frequency, F2 frequency, and /s/ skewness had the most influence on perceived sexual orientation. Their findings "did not support the conjecture that GLB people's speech was the result of global scaling towards opposite-sex values" and "listeners were not listening for global indices of masculinity and femininity when making judgements of perceived sexual orientation" (p. 224). The authors suggest that factors beyond sexual orientation, such as using "a habitual clear speech style" or the newer variant afforded by a regional sound change in progress, may influence which voices listeners perceive as sounding gay (p. 237).

Podesva (2007) approached the inquiry into features associated with gay men in a case study investigating the falsetto phonation of a single speaker, Heath, by analyzing three 30-minute recordings from interactions in his daily life. The researcher equipped Heath with a Walkman-sized cassette recorder and instructed him to record conversations 
in which it would be appropriate to do so. (The researcher was not present while speech samples were recorded.) Podesva found that the speaker demonstrated considerable variation depending on the context. For example, during a social event with friends, Heath produced a falsetto that is more frequent and longer in duration as well as higher and wider in f0 range as compared to his speech while at work as a medical professional. This finding highlights that even if linguistics experiments can find which speech features are associated with "gay-sounding" voices, these features and their rates of use are not universal: they will vary based on setting, interlocutors, and several other factors that influence a person's vocal behaviors. Furthermore, Podesva writes:

The use of falsetto to perform expressiveness may in turn be interpreted as gay, largely due to the dominant ideology that performing expressiveness is a non-normative behavior for men ... By performing expressiveness, Heath relinquishes not only power, but heteronormative masculinity, thus completing the link between falsetto and gay meaning. (p. 495)

Podesva spotlighted the fact that the connection between speech features and perceptions that a speaker is gay are not direct. The association between a given acoustic feature and gayness is "constituted and mediated by the relation of language to stances, social acts, social activities, and other social constructs" about what is normatively masculine (i.e. "this male voice sounds expressive, men are not supposed to be expressive, therefore he must be gay') (Ochs, 1992, p. 337). As Podesva later concluded, "phonetic features index a host of stances, acts, and activities that are conventionally associated with sexual identities" (Eckert \& Podesva, 2011, p. 9). 
Zimman (2013) contributed a similar perspective to the body of linguistic articles on gay-sounding voices. Based on his review of past literature on the acoustic correlates of perceived sexuality, he argued that:

the contradictions that appear across studies of gay-sounding voices are best understood as evidence that there is no single gay-sounding style, but rather a multiplicity of styles that can be interpreted as indexing sexuality by virtue of their departure from normative masculinity. (p. 2)

He recruited 15 speakers for the study: 5 cis gay men, 5 cis straight men, 1 trans straight man, and 4 trans men who identified their sexuality as queer. He conducted ethnographic interviews with participants and recorded them reading an elicitation passage. Zimman took an excerpt of the recordings and analyzed them for 7 acoustic features: mean fundamental frequency, the first and second formant frequencies (F1 and F2), vowel dispersion, creaky voice quality, and the frequency profile of /s/ as measured by center of gravity and spectral skew. He also used these excerpts in a perceptual experiment where 43 listeners were asked to rate the speakers' age, height, sexual orientation, and ethnicity using 5-point Likert scales online. Zimman found that "the gay men were significantly more gay-sounding than the straight men $(\mathrm{p}<0.001)$, as were the trans men $(\mathrm{p}<0.001)$, while the differences between the trans men and the gay men did not reach statistical significance" (p. 18). The acoustic analysis revealed that low mean f0, higher rate of words produced with creak, and an /s/ with a more negative skew (i.e. a skew toward higher frequencies) all correlated significantly with a voice being rated as gay-sounding. However, an examination of inter-group differences demonstrated both similarities and 
differences between the cis and trans speakers labeled as gay-sounding, providing evidence for "the diversity that exists among gay-sounding phonetic styles" (p. 26). Zimman concludes by stating:

Looking at variation among gay-sounding speakers reveals one of the linguistic manifestations of hegemonic masculinity, wherein a narrow range of acceptable masculinities is valorized while others are stigmatized through association with femininity or homoeroticism. . . do not lose sight of the diverse masculinities subjugated by hegemonic forces. (pp. 33-34)

Voices that are deemed "gay" come from a variety of speakers, and this judgement is a comment on their masculinity rather than solely on their sexual orientation.

In summary, linguistic research does not attest the existence of a unitary "gay voice.” In Munson's words, “when you call it the gay voice, you're implying every gay man uses it, and you're implying that only gay men use it, and I think it's pretty clear that neither of those is true" (Garfield \& Vuolo, 2014, 8:39 - 8:47). The label "gay voice" at best describes constellations of speech features that have come to be associated with stances that index non-normative masculine behavior for many speakers of English in North America at this point in time. However, this essentializing term erases the fact that "there is no one-to-one mapping between a person's sexual orientation and how they speak" (Smyth \& Rogers, 2008, p. 129). Describing someone's voice as "gay" has as much to do with their gendered behaviors as it does with their sexuality. Deeming that a speaker's voice is gay-sounding will also be contingent on the experiences and attitudes of the listener ascribing the label. 
In this thesis, I investigate discourses about "gay voice" online for two reasons. First, the literature on gay-sounding voices mainly consists of production and perception studies of acoustic features. Only one of the studies that I have come across examined discourses about gay-sounding voices. Mann (2016) analyzed interviews with 8 selfidentified gay men to attitudes about sounding gay. He paired this information with results from a perceptual survey to test the "Attitude and Perception Hypothesis: Gay men with negative attitudes toward sounding gay are less likely to be perceived as gay by perception study judges than gay men with neutral or positive attitudes toward sounding gay" (p. 206). Since discourse analysis was not the sole focus of this study and data came from a small number of participants, I believe there is still more work to be done in this area.

Second, none of the studies about sounding gay that I have found look at data from online interaction. Researchers can now readily access data from "Internet-based applications ... that allow the creation and exchange of user-generated content" (Kaplan \& Haenlein, 2010, p. 61; as cited in Törnberg \& Törnberg, 2016, p. 403). Discussions that occur on forums, social networks, wikis, and other such websites can help scholars more fully understand how societal discourses are (re)produced as compared to looking at traditional media sources (e.g. newspapers) which reflect the perspectives of a small number of authors (Törnberg \& Törnberg, 2016, p. 403). Examining the discussions taking place online about "gay voice" can provide us with one example of the ways in which cultural ideas about gender and sexuality inform such conversations. 


\subsection{Public Discussions of Sounding Gay}

In this section, I describe a recent series of media events that address gaysounding voices. The documentary Do I Sound Gay?” (Thorpe \& Gertler, 2014) gave rise to a surge in popular and professional discourses related to "gay voice" in the media. The film centers on director David Thorpe and his desire to change his voice. What begins as a narrated inquiry into the features associated with (white) gay male speech turns into an exploration of the larger socio-cultural issues involved, in which Thorpe "wryly treats his anxieties about his 'gay' voice as an exercise in self-improvement, and winds up with a compelling portrait of internalized homophobia and liberation" (Taylor, 2015, II1). There have been over 30 festival and theatrical screenings of the documentary around the world, many of which occurred between February and June of 2015 (See the Film, n.d.).

In July 2015, Terry Gross of National Public Radio (NPR) interviewed Thorpe and Susan Sankin, a speech pathologist featured in the documentary, on the program Fresh Air in an interview entitled "Filmmaker and Speech Pathologist Weigh In On What It Means to 'Sound Gay'” (Gross, 2015). The following day, Sameer ud Dowla Khan, assistant professor of linguistics at Reed College, published an open letter to the program's host that outlined the ways in which:

the opinions expressed in the interview [were] not only inaccurate, but also offensive and damaging ... Not only is it inaccurate to label minorities as the only ones who convey their identities through their 
speech, it also perpetuates a misguided belief that there is a "natural" way to speak ... This will strengthen a narrow-minded view that gay men (and other minorities) are going out of their way to just sound that way, implying that even in their speech, their behavior is unnatural and undesirable. (Khan, 2015)

This series of events highlights that whose voices we pay attention to and seek to understand is imbued with power dynamics.

In March 2017, Fasoli, Maass, Paladino, and Sulpizio published "Gay- and Lesbian-Sounding Auditory Cues Elicit Stereotyping and Discrimination." The researchers ask 276 participants recruited from a large Italian university to rate four people based on an audio clip of his/her voice on measures regarding personality traits, interests, suitability for friendship, and potential employability as the CEO of a fictional company. Speech samples were borrowed from a previous study (Sulpizio, Fasoli, Maass, Paladino, Vespignani, Eyssel, \& Bentler, 2015) and consisted of one-sentence-long audio clips from four participants: "two speakers who had the highest likelihood to be perceived as gay and two speakers who were consistently perceived as heterosexual" (Fasoli et al., 2017 , p. 4). They find that male participants indicated that they were less likely to befriend the people behind the "gay-sounding" voices and found both "gay- and lesbiansounding" speakers to be less qualified for the fictitious CEO position. (The same results were not obtained in the female participant group.) This study supports the idea that there can be material consequences for having a gay-sounding voice.

Although the authors had written on the topic on at least two previous occasions (Sulpizio et al., 2015; Fasoli, Maass, \& Sulpizio, 2016), this article, in particular, was 
covered by several news outlets online within the week after its publication (Meredith, 2017; Fernandez, 2017; Kale, 2017; Reynolds, 2017; Gonella, 2017; Beresford, 2017; Besanvalle, 2017; Jones, 2017; Brook, 2017; Valens, 2017). Kale (2017) reports on an interview with Fasoli in which the researcher presents a summary of the study and findings in accessible language. Fasoli's words from this interview were widely cited in the other articles listed above. Five days later, Gonella (2017) quotes David Thorpe, "the filmmaker behind the documentary Do I Sound Gay?” (\$7-9) about his reactions to Fasoli et al.'s findings. Thorpe's words were also cited in Reynolds (2017) and Besanvalle (2017). Although all of the ten articles mentioned above contain some permutation of "gay voice," "sound(s) gay," and/or “gay-sounding," few contain an actual elaboration of what is meant by these phrases or complex interplay between gender and sexuality that is involved with the label. One notable exception comes from Reynolds (2017), which characterizes "gay voice" as "a gender-nonconforming way of speaking that some use to identify queer people, even before disclosure of sexual orientation and gender identity. The 'gay voice,' it found, was not limited to gay people, many of which are also 'heterosexual-sounding’" (\$9). Brook (2017) mentions, "previous research has been conducted into whether people can accurately determine sexuality based on voice alone" but does not provide further detail on the findings of such studies (II4). This brief review of media discussions demonstrates that more dialogue is needed between popular notions of sounding gay and linguistic perspectives on the topic. 


\subsection{Definition of Persona}

In the analysis in Chapter 4, I will be using the term "persona." Johnstone (2017) defined as: "a way of being and acting associated not just with a social identity in an abstract sense, but with its embodiment in a character, imagined or actually performed" (as cited in D’Onofrio, 2019, p. 347). D’Onofrio (2019) elaborates on this definition:

Rather than members of social groups or individual personalities as psychologically defined, personae constitute holistic, ideologized character types that are identifiable in the imaginations of communities, sometimes even explicitly labelled, such as the "Valley Girl" (D'Onofrio, 2015), or the "yinzer" (Johnstone, Andrus, \& Danielson, 2006). These imagined characters are specified for macrosocial, personality-based, and behavioral characteristics, and of course, linguistic styles, with individual speakers dynamically enacting different personae in different interactional moments. (p. 347)

This concept is important to understand for this study because sounding gay is often linked to a stereotypically gay persona that exists in our cultural imagination, particularly reinforced in media portrayals. For example, the description of the "Camp Gay" character on TVtropes.org describes this caricature by noting that he is "flamboyant in his dress, speech, mannerisms, and interests," "will often speak with a lisp," and uses "near-opaque slang" (Camp Gay, n.d.). Examples given on that page include Emory from The Boys in the Band (1970), Buddy Cole in The Kids in the Hall (1988-1995), and Jack from Will \& Grace (1998-2006, 2017-2020). 


\subsection{Research Questions}

In this thesis, I investigated discourses surrounding the terms "gay voice" and "sound gay" on the popular U.S.-based online forum Reddit. By collecting a database of Reddit posts containing the search terms and then examining that data using topic modeling, I identified posts related to gender and sexuality which could be further examined using discourse analysis. This process informed the first research question of the study:

1. What themes characterize discussions about "gay voice" and "sound gay" on Reddit? In other words, when users of Reddit are discussing "gay voice" what are they talking about?

Topic modeling revealed that the word "feminine" was found across several posts in the corpus. This finding was expected: as Zimman (2013) noted, "regardless of how frequent non-normative masculine gender expressions actually occur among gay men, there is a clear ideological link between femininity and male homosexuality" (p. 8; emphasis in original). I focused on posts that contained a high rate of the word "feminine" in the discourse analysis phase of the research in hopes of unpacking some of "the deep and complex cultural links between gender normativity and sexuality" that underlie discussions of gay-sounding voices (Zimman, 2013, p. 8). This finding informed the second and third research questions of the study:

2. What linguistic features are employed by Reddit users in interactions about gay voice and femininity, and to what effect? 
3. What discourse moves are made by Reddit users in interactions about gay voice and femininity, and to what effect? 


\section{Chapter 3: Methodology}

In the first half of this chapter, I review of the analytic methods used in this study: topic modeling, transitivity analysis, and tactics of intersubjectivity analysis. In the second half, I describe the source of the online forum data, how it was collected, and the specific steps I took to analyze it. I finish with an overview of the stages of the methodology.

\subsection{Review of Analytic Methods}

The design of the present study draws on techniques from corpus linguistics and discourse analysis in order to answer the research questions presented in the previous section. Corpus linguistics refers to the practice of compiling a large principled collection

of language data and performing a computer-assisted analysis of the texts (Conrad, 2017). In this way, the current study could be described as adopting a corpus-assisted approach. However, the research design at hand does not use a traditional concordancer software such as MonoConc (Anthony, 2019) or draw on a pre-existing corpus-concordancer package such as the Corpus of Contemporary American English (Davies, 2008). Furthermore, I do not utilize techniques typical to many corpus studies, such as keyword in context (KWIC) and collocation searches.

Following Törnberg and Törnberg (2016), I instead draw on a technique known as topic modeling, which uses statistical modeling to infer topics based on a corpus of text. 
A colleague wrote a programming script that automatically extracted the linguistic contents of online forum posts from the website Reddit into text documents. Next, I used a website that performs topic modeling on the corpus to inductively generate a list of topics (Mimno, 2018). I went through this process to select a subset of Reddit posts on which to perform a discourse analysis without "cherry-picking" (or selecting the most convenient examples) - a common issue encountered in this type of investigation (Törnberg and Törnberg, 2016, p. 134).

The word "topic" is used throughout linguistics and has different meanings depending on the subfield and type of analysis in which one finds it. Past scholars have made a distinction between discourse topic and grammatical topic: "a discourse topic, which is what a given discourse unit is about and hence is a discourse notion, should be distinguished from a topic that appears in individual sentences, a grammatical expression" (Vermeulen, 2016). In this paper, I use the word "topic" to refer to the discourse notion. I understand this concept to be similar to the idea of theme used in the study of literature: "An idea that recurs in or pervades a [text]" (Cummins, 2017). I provide a mathematically-based definition of "topic" in the next paragraph to help clarify how the algorithm operationalizes the discourse notion sense of the word.

Although discourse analysis (DA) is defined many ways in many fields, the definition I use and one common in linguistics is the practice of examining "structure [that exists] beyond the unit of the sentence" (Onwuegbuzie \& Denham, 2015). A researcher explores "the themes or issues being discussed" through an analysis of "how [the structure of language] functions to make meaning in specific contexts" (Gee, 2011, 
p. 6). DA can be conducted in a variety of ways, using both quantitative and qualitative approaches. In this study, I combine both quantitative and qualitative techniques. Through the use of transitivity analysis (Halliday \& Matthiessen, 2004) (see §3.1.2), I identify the linguistic features that authors select to construct their points in order to understand how they are portraying the issue they discuss. The qualitative portion of the analysis is implemented using the tactics of intersubjectivity (Bucholtz \& Hall, 2004a, 2004b, 2009) (see §3.1.3).

\subsubsection{Topic Modeling}

Topic modeling refers to a variety of methods and algorithms that extract topics from a collection of text-based documents (Graham, Weingart, \& Milligan, 2018, I6; Törnberg and Törnberg, 2016, p. 405). In this context, a topic is "a list of words that occur in statistically meaningful ways” (Graham, Weingart, \& Milligan, 2018, I66) or, more specifically, "a list of words with different assigned probabilities" (Törnberg and Törnberg, 2016, p. 405). In essence, topic modeling aims to identify the K most salient "recurring clusters of co-occurring words" (Törnberg and Törnberg, 2016, p. 405) within a corpus, where $\mathrm{K}$ equals the number of topics set by the user before the analysis is conducted (Boyd-Graber, 2013, 0:40).

While there are several statistical methods for topic modeling, the website I use in this study (Mimno, 2018) uses the latent Dirichlet allocation (LDA) algorithm created by Blei, $\mathrm{Ng}$, and Jordan (2003). LDA is a commonly-used algorithm that extrapolates missing information, or latent variables (i.e. topics), from a statistical modeling of the 
words and documents that comprise the corpus. This model assumes that "each topic is a distribution over words, and (...) each document is a distribution over topics" (BoydGraber, 2013, 7:35-7:55). Thus, "there are two multinomial distributions that explain what topics are associated with which words, and which documents are associated with which topics" (Boyd-Graber, 2013, 9:14-9:23). For the model to discover the topics of a corpus, it:

assumes that any [document] is composed (by an author) by selecting words from possible baskets of words where each basket corresponds to a topic. If that is true, then it becomes possible to mathematically decompose a text into the probable baskets from whence the words first came. The tool goes through this process over and over again until it settles on the most likely distribution of words into baskets, which we call topics (Graham, Weingart, \& Milligan, 2018, I77; emphasis mine).

A final list of topics is generated by recursively comparing which topics are expressed by the words within each document and how much each document is about each of these topics until a fitting summary is reached (Boyd-Graber, 2013). The result is "a pre-set number of topics, where each topic has a list of words with different probabilities, and each document is linked to a list of topics with different probabilities" (Törnberg and Törnberg, 2016, p. 405). (For more information on the mathematics involved, see BoydGraber, 2013). In practice, this output takes the form of a table with K number of rows, each comprised of the 10-20 keywords most related to this topic. Additionally, the top documents, or a list of the documents most strongly associated with each topic, are also provided (Törnberg and Törnberg, 2016, p. 405). 
Topic modeling "offers a way to get a corpus-level view of the major themes"

(Boyd-Graber, 2013, 0:02-0:04) and thus "constitutes an enriching complement to CDA, aiding discovery and adding analytical rigor” (Törnberg and Törnberg, 2016, p. 402).

This is because:

topic modeling is similar to some methods applied within corpus linguistics (CL) and constitutes a valuable complement to discourse analysis by providing an overview or 'content map' of immense sets of documents, revealing small but systematic patterns and tendencies in the data. [DA] can contribute by enabling a more thorough and systematic qualitative analysis that goes beyond superficial explorative findings and increases the ambition by reaching into the realm of understanding and explanation. (Törnberg and Törnberg, 2016, p. 404)

In this study, topic modeling was used to answer the first research question regarding what themes characterize online forum discussions about "gay voice" and "sound* gay." It was also used to determine empirically which forum posts were most salient for discourse analysis.

\subsubsection{Transitivity Analysis}

The word "transitivity" can refer to a variety of concepts within linguistics. In the context of English syntax, for example, it is defined as the number of arguments that a predicate can take. I use the term transitivity to signify a related but more general concept based on its definition from the subfield of Systemic Functional Linguistics:

"grammatical patterns [that express] 'who is doing what to whom when where why and how"' (Eggins, 2008, p. 110). Transitivity analysis examines the verbs (or process types) 
that language users select to represent their experiences, the participants that these imply, and the circumstances in which these processes are set. Analyzing these aspects of word choice is a useful tool because:

Transitivity patterns represent the encoding of experiential meanings: meanings about the world, about experience, about how we perceive and experience what is going on. By examining the Transitivity patterns in text, we can explain how the field of the situation is being constructed, i.e. we can describe 'what is being talked about' and how shifts in the field are achieved. (p. 249)

In this study, transitivity analysis was used to answer the second research question regarding what linguistic features were employed by Reddit users in interactions about gay voice and femininity, and to what effect. To quote Eggins (2008), when forming any given sentence that a language user utters or writes, they must select a process type ("realized in the verbal group of the clause"), participants ("realized in the nominal groups"), and circumstances ("expressed through adverbial groups or prepositional phrases”) (pp. 214-215). In the next two subsections, I briefly define the various options for process types and circumstances.

\subsubsection{Process Types}

There are six main categories of process types: mental, material, verbal, behavioral, existential, and relational. See Figure 3.1 for a visual representation of what these process types entail and how they are related to one another from Moore (2015). (For the participants associated with each process type, please see Appendix A.) The definitions of these process types are: 
- Material: "some entity does something, undertakes some action" (p. 215)

- Mental: "thinking or feeling" (p. 225)

- Verbal: "verbal action: saying and all its many synonyms, including symbolic exchanges of meaning" (p. 235)

- Behavioral: "physiological and psychological behavior [by a conscious being]" (p. 233)

- Existential: "where things are simply stated to exist" (p. 237)

- Relational: "where things are stated to exist in relation to other things (attributes or identities)" (pp. 237-238)

The three process types that I discuss in this paper are material, mental, and relational. Material processes represent actions and events that happen in the outer world, that are some sense tangible to a number of people. For example, "Diana gave some blood." Mental processes refer to cognition, perception, and affect. These are inner states and processes that are not perceptible to outside observers. For example, "Diana thought she should give blood." (N.B.: All examples given in this paragraph are borrowed from Eggins, 2008, pp. 213-214.)

Relational processes are constructions "where things are stated to exist in relation to other things" (Eggins, 2008, pp. 237-238). For example, "Diana is a blood donor." In this paper, I discuss two subtypes of relational processes in particular: attributive intensive and identifying intensive processes. An intensive process "involves establishing a relationship between two terms, where the relationship is expressed by the verb 'to be' or a synonym" (p. 239). Each subtype is defined in the following ways: 
- Attributive intensive: "a quality, classification or descriptive epithet (Attribute) is assigned to a participant (Carrier) . . . the meaning of an attributive intensive is that ' $\mathrm{x}$ is a member of a the class a'" (Eggins, 2008, p. 239).

- Identifying intensive: "the meaning of an identifying intensive is that ' $x$ serves to define the identity of y'... [it involves] a token (that which stands for what is being defined) and a value (that which defines)" (pp. 241-242).

In attributive intensive processes, some quality is assigned to a carrier to characterize or classify it. For example, "Diana is healthy." In identifying intensive processes, some value is used to define a participant. For example, "Diana is the healthiest one here." (N.B.: All examples given in this paragraph are simplified versions of those listed in Eggins, 2008, pp. 240-242.) 


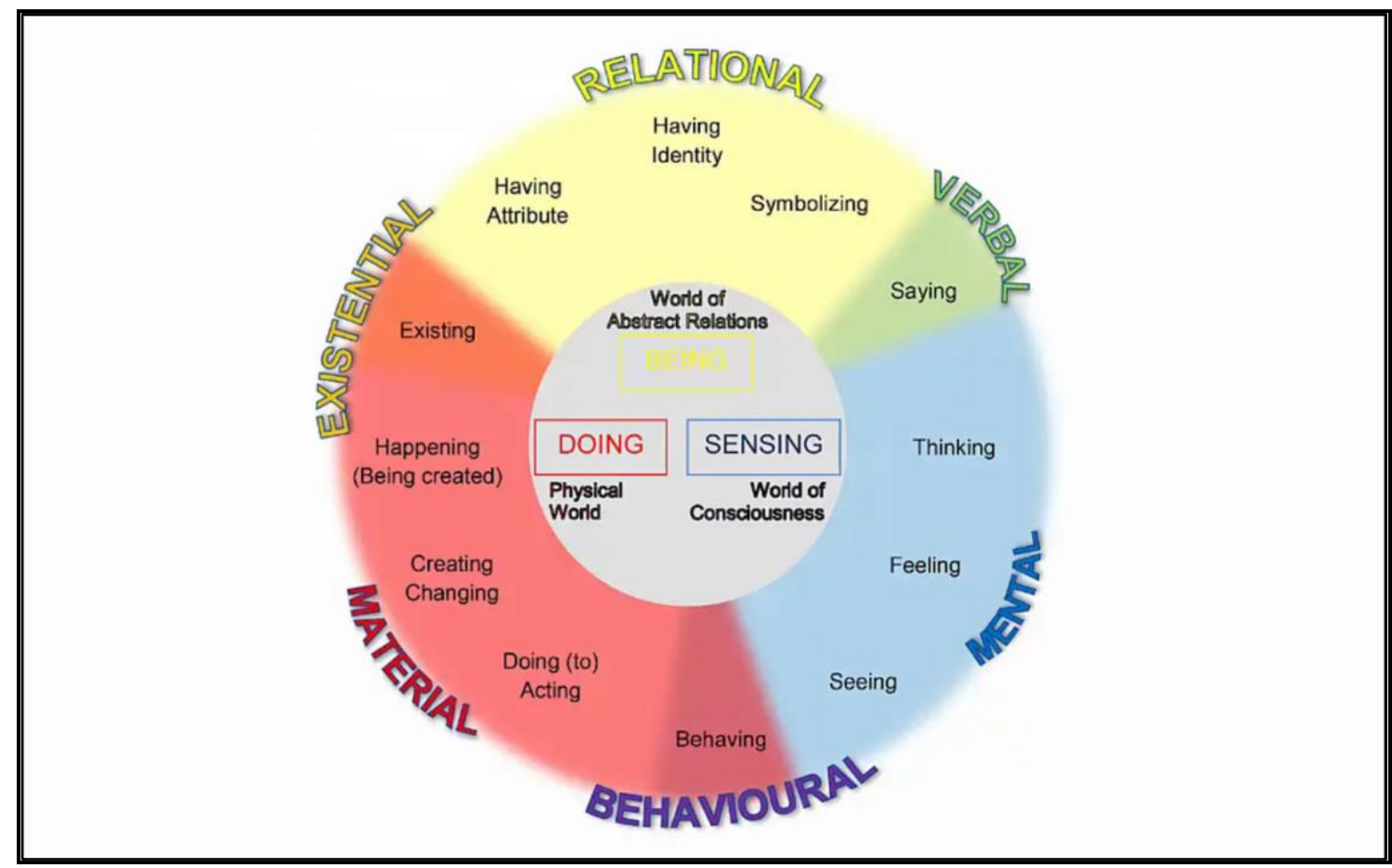

Eigure 31. The semantic field of process types in transitivity analysis.

Reproduced from Moore (2015)

\subsubsection{Circumstances}

Circumstances are the elements of a sentence that provide contextual information about when, where, why or how the process type occurred. As noted above, circumstances are "realized by adverbial groups or prepositional phrases" (Eggins, 2008, p. 215). See Table 3.1 for a list of the types of circumstances examined in transitivity analysis. Although I coded for circumstances in the transitivity analysis, the token counts are low. Because of this, I will not discuss circumstantial elements further in this paper. 
Table 3.1

Circumstances in Transitivity Analysis

\begin{tabular}{|l|l|}
\hline Circumstances & Questions about context that it answers \\
\hline location/time & $\begin{array}{l}\text { When? (temporal) } \\
\text { Where? (spatial) }\end{array}$ \\
\hline extent & $\begin{array}{l}\text { How long? (duration) } \\
\text { How far? (spatial distance) }\end{array}$ \\
\hline manner & $\begin{array}{l}\text { How? With what? (means) } \\
\text { How? How . .ly? (quality) } \\
\text { What . . like? (comparison) }\end{array}$ \\
\hline cause & $\begin{array}{l}\text { Why? (cause) } \\
\text { What for? (reason) } \\
\text { Who? Who for? (behalf) }\end{array}$ \\
\hline accompaniment & With whom? \\
\hline matter & What about? \\
\hline role & What as? \\
\hline
\end{tabular}

\subsubsection{Tactics of Intersubjectivity}

I draw on the "tactics of intersubjectivity" set forth by Bucholtz and Hall (2004a, 2004b, 2009) to analyze what discourse moves are made by Reddit users in interactions about gay voice and femininity, and to what ends (the third research question of this study). Intersubjectivity can be defined as "the relation between one actor's subjectivity and another's" (Du Bois, 2007, p. 140) and thus refers to the concept that each individual has their subjective experience of reality. Obviously, language (among other social semiotic systems) is one way in which we relate our respective understandings of the stimuli that we encounter to one another. Bucholtz and Hall's framework is a valuable lens through which view issues of language and identity. Other scholars researching 
computer-mediated communication (Karimzad \& Sibgatullina, 2017) have used the framework laid out by Bucholtz and Hall (2004a, 2004b, 2009) to aid in their analysis.

Bucholtz and Hall (2004a) outline "three different but interrelated concepts central to identity": markedness, essentialism, and institutional power. The concept of markedness refers to "situations in which normative and non-normative categories are established" (p. 370). The unmarked group, typically occupied by those with the most power and/or resource, designates itself as the default or "norm" and erases evidence that contradicts this vision: "the group with the greater power establishes a vertical relation in terms beneficial to itself $[. .$.$] the group constitutes itself as the norm from which all others$ diverge" (p. 372). Essentialism is defined as "overgeneralized notions of similarity and difference" (p. 370). Thus an 'us versus them' mentality is established: intergroup similarities are disregarded and/or intragroup variation is ignored. These "similarities and differences become organized hierarchically in social contexts" with material consequences for the respective groups involved (2004, p. 369). Lastly, institutional power is characterized as the authority given to those affiliated with an institution or some other sphere of influence within the social context.

Within each of these three central concepts to identity, Bucholtz and Hall (2004a, 2004b, 2009) provide two "countervailing" tactics which position a given identity within the social landscape: adequation and distinction; authentication and denaturalization; authorization and illegitimation, respectively (for definitions, see Table 3.2 below). I provide examples of each of the tactics in the subsections that follow, which were taken from Mulliner (2017). 
Table 3.2

Bucholtz and Hall's Tactics of Intersubjectivity

\begin{tabular}{|l|l|l|}
\hline \multicolumn{1}{|c|}{ Concept } & \multicolumn{1}{|c|}{ Tactic } & \multicolumn{1}{c|}{ Definition } \\
\hline Markedness & Adequation & $\begin{array}{l}\text { "differences between [social actors] are temporarily } \\
\text { erased or backgrounded while similarities are } \\
\text { highlighted or emphasized" } \\
\text { (2004a, p. 496) }\end{array}$ \\
\cline { 2 - 4 } & Distinction & $\begin{array}{l}\text { "the ideological construction of social difference } \\
\text { through the erasure of likeness and the highlighting } \\
\text { of unlikeness" } \\
\text { (2004a, p. 496) }\end{array}$ \\
\hline Essentialism & Authentication & $\begin{array}{l}\text { "[claims about] what sorts of language and } \\
\text { language users count as 'genuine' for a given } \\
\text { purpose" } \\
\text { (2009, p. 24) }\end{array}$ \\
\cline { 2 - 4 } & Denaturalization & $\begin{array}{l}\text { "claims to the inevitability or inherent rightness of } \\
\text { identities are subverted. What is called attention to } \\
\text { instead are the ways in which identity is crafted, } \\
\text { fragmented, problematic or false." } \\
\text { (2009, p. 24) }\end{array}$ \\
\hline Institutional & Authorization & $\begin{array}{l}\text { "the attempt to legitimate an identity through an } \\
\text { institutional or other authority" } \\
\text { (2004b, p. 386) }\end{array}$ \\
\cline { 2 - 4 } & Illegitimation & $\begin{array}{l}\text { "addresses the ways in which identities are } \\
\text { dismissed, censored or simply ignored by } \\
\text { [structures of institutionalised power and ideology, } \\
\text { whether local or translocal]" } \\
\text { (2009, p. 24) }\end{array}$ \\
\hline & &
\end{tabular}

\subsubsection{Concept: Markedness}

Example (1) demonstrates how YouTube user Top10 identifies himself as a speaker who "has a gay voice" and yet self-identifies as heterosexual:

(1) Top10: But I am straight, but yet have a gay voice. I never thought to myself, 'hmm, tomorrow i am going to start talking camp'. I grew up with that as a normality for me. 
This user employs the tactic of adequation to acknowledge similarity between himself and those who also identify as having a "gay voice," noting that his verbal mannerisms reflect his default speaking voice and not a style that he performs. This discourse move disrupts the essentialist reading between sexual orientation and speech patterns. In contrast, viewer comments such as example (2) juxtapose "sounding gay" with an invisible normative way of speaking, thus demonstrating the tactic of distinction:

(2) Mark G: (...) I think that males who do speak "gay" are definitely trying to present something to the world about themselves (...) Personally I prefer people who I would say sound "normal" (whatever that is). (...)

Mark $G$ acknowledges that defining normal is a subjective exercise, but does not acknowledge that on a societal scale, existing power structures make this decision for us (i.e. normal $=$ straight white wealthy educated monolingual male speakers of a nonstigmatized variety of American English). Thus, in this case, the tactic of distinction serves to position speakers who "sound gay" as deviations from an unrecognized norm.

\subsubsection{Concept: Essentialism}

In example (3), kay jay's comments support an oversimplified understanding of "gay voice" through the tactic of authentication:

(3) kay jay: I am very pro-gay, but most gay men do in fact have a uniqueness to their voice that distinguishes them from heterosexual men. THERE IS NOTHING WRONG WITH THAT. In fact, I have seen videos of gay men who put down "femme" gay men who seem competely [sic] oblivious to the fact that they also have this distinctive tone to their voice. 
This user reinforces with the stereotype that the majority of gay men "sound gay" in a way that is recognizable to others. Then, through the use of the words "uniqueness," "distinguishes," and "distinctive," the user insinuates that this "tone of voice" is a bounded phenomenon exclusive to the gay community. In contrast, user ancient mami applies the tactic of denaturalization through the comment in example (4) in which she/he openly rejects the notion of an essentialist interpretation of "sounding gay":

(4) ancient mami: excuse me but what does sounding gay even mean ? the only way a person would sound gay is if they'd literally come through and say ' I identify as $\mathrm{x}$ gender and guess what! I'm attracted to it as well ."

This user delineates the sole way in which one's sexual orientation could be discerned from their speech: if they told you directly how they self-identified with regards to both gender identity and sexual/romantic preferences. Thus, they denaturalize the idea that a person can sound gay based on acoustic features in their voice.

\subsubsection{Concept: Institutional Power}

Examples (5) and (6) are both drawn from radio interviews featuring language professionals: Benjamin Munson, speech scientist, and Susan Sankin, speech language pathologist, respectively. In both cases, Munson and Sankin were invited for an interview because of their formal training in language-related matters, thus imbuing them with the authority associated with their institutional accomplishments. In example (5), Munson applies the tactic of authorization through his position as an expert guest: 
(5) Benjamin Munson: Speech language pathologists work on disorder, they don't work on difference. And what we're talking about here is not a pathology, we're talking about normal linguistic variation. (Mantle, 2014)

He directly emphasizes that the phonetic features associated with so-called "gay voice" are "difference" and thus "normal," as opposed to being a "disorder" and therefore pathological. Conversely, Sankin uses negative medical terminology to describe the prevalence of high-rising terminals (one of the features she lists as characteristic of "gay voice" earlier in the same interview):

(6) Susan Sankin: The upspeak, definitely. It's just across the genders, it's across age categories. It's an epidemic . . . It's been around for a while - I would say at least the last couple of years, but maybe longer than that. Initially when I heard it, it was among younger women. It seems now, though, that men have caught on as well, and it's become as contagious as the common cold. Everybody is using it. (Gross, 2015)

Stating that the perceived overuse of high-rising terminals is an "epidemic" that is "as contagious as the common cold" relates this voice quality feature with a discourse of disease. Paired with her position as a language professional, her statements communicate a message of illegitimation.

3.2 Data

3.2.1 Source of the Data 
The text analyzed was collected from the website Reddit, a popular U.S.-based online platform for creating forums. Users submit content and vote for which posts are displayed most prominently through a system known as upvoting ("Reddit," n.d.). Any visitor to the site can read the discussions contained, but must create an account in order to submit, vote on, or moderate content. At the time of writing, Reddit had over 3 million registered users, who post an average 2.8 million new comments per day (Smith, 2019). The site is comprised of several thousand message boards on specific topics, known as subreddits ("Reddit," n.d.). In the words of site employees,

the single most important thing to understand about reddit [...] is that reddit is not a single monolithic site. It's a platform for creating communities, and is made up of thousands of active communities (known as "subreddits"), which are devoted to all sorts of different topics and are created and maintained by regular users. ("How reddit works," 2014, ๆ2; emphasis in original)

There are currently over 150,000 active subreddits (Smith, 2019). Although the site started as a forum focused mainly on science and technology-related discussions, the current range of topics now discussed is immense. Activity on some of the more popular subreddits (as determined by the number of users who have subscribed to receive updates from it) has been covered by a number of traditional news media outlets. For example, the subreddit "r/the_Donald" has been cited (e.g. Feinberg, 2017; Romano, 2017) as a fervent online meeting place for those in favor of the politics of Donald Trump ("Reddit," n.d., I17). Furthermore, a number of well-known American figures have participated in online press conference-style interactions on the site via the subreddit "r/AMA" (Ask Me Anything), such as Bill Gates and Barack Obama (“Reddit,” n.d., ๆ19). 
Reddit is a rich source of linguistic data for discourse analysis. It is one of the most widely-visited websites on the internet: it is currently the sixth most popular website in the United States and ranked nineteenth internationally ("Reddit.com Traffic Statistics," n.d.). While the site is multilingual and has users from over 200 countries, the majority of interaction occurs in English (Smith, 2017; "Reddit," n.d.). Users from the United States comprise around $43.2 \%$ of the site's visitors ("Reddit.com Traffic Statistics," n.d.). Thus, the discussions occurring on Reddit can be said to be one representation of discourses currently found among speakers of English, in the United States in particular, surrounding the perception being analyzed in the current study. However, it is worth noting that research outside of the site has found that the majority of Reddit users tend to be young, male, college-educated, and politically liberal (Sattelberg, 2019). Nevertheless, I draw on online discussions in contrast to traditional media sources since the perception I am investigating is not often discussed explicitly in the latter. (Notable exceptions include the documentary Do I Sound Gay? and the related NPR Fresh Air segment discussed in §2.2.) Even when gay-sounding voices are discussed in the media, these conversations still represent the perspectives of a smaller number of individuals from the overall population than online forum conversations do.

Additionally, text-based online mediums lend themselves easily to asking questions and expressing opinions in a context that is removed from the pressures and considerations on in-person interactions. "The discussions occurring on Reddit are anonymous: (1) to register, one must only provide a username, password, and email address, and (2) Reddit prohibits posts containing personal and confidential content, and 
enforces this policy through tactics such as removing content and suspending user accounts ("Reddit Content Policy," n.d.). Using Reddit data provides a unique opportunity to access discourses from a large and diverse group of participants in a context in which they can converse without being directly identifiable.

In order to find Reddit queries that discuss the perception under investigation, I selected the search terms "sound OR sounds OR sounded OR sounding gay" (hereafter "sound* gay") and "gay voice." These were the most common lexical bundles used by journalists in the media coverage of Fasoli, Maass, Paladino, and Sulpizio (2017) (see §2.2). Moreover, the top Google results for each of the search terms suggest that the majority of Reddit queries they retrieve discuss auditory perception as opposed to solely figurative uses of the phrases.

\subsubsection{Data Collection}

The data for this research was collected in April 2018. The data collection process was carried out by a Python script that converted relevant webpages from Reddit into text documents.1 In the first part of the procedure, the script consulted Google's application programming interface (API) for the first 100 results for the search "gay voice" AND “sound gay” OR “sounds gay” OR “sounded gay” OR “sounding gay” followed by "site:reddit.com." The script converted the search results into a list of hyperlinks, and then eliminated duplicates across the searches and any resulting links from the websites other than Reddit. The links resulting from these searches directed the script to Reddit 
posts (i.e. a webpage containing a main question or topic posted by a user with comments in response from the community).

Next, the script converted the resulting list of hyperlinks into individual documents. That is, the text found on the webpage that each link refers to was extracted, or scraped. In this process, the script defined a word as a cluster of characters that begin or end with either a space or common punctuation marks (e.g. ", "“") based on the Regex parameters for word boundaries ("Regular Expression Reference: Word Boundaries," n.d.). All of the words contained on a given webpage were ordered sequentially with a single space between each into a text file. The script deleted any files that consist of fewer than 1000 words from the corpus for technical reasons related to the statistical analysis (cf. Törnberg \& Törnberg, 2016, p. 410). In the current study, 76 documents resulted from this process.

Next, the script eliminates the most frequently used function words (e.g. the, and) from each document, commonly referred to as stopwords in computational linguistics ("Stop words," n.d.). In this study, the list of stopwords is borrowed from the code provided by the gensim software (Řehůřek, n.d.). The remaining words within each document are stemmed using the Porter (1980) stemming algorithm. This process is included to "reduce inflectional forms and sometimes derivationally related forms of a word to a common base form," and thus decrease the number of words under consideration in the later steps of the analysis (e.g. am, are, is $\rightarrow$ be; car, cars, car's, cars' $^{\prime} \rightarrow$ car) (Manning, Raghavan, \& Schütze, 2009, p. 32). 
To review, the Python script retrieved comments from 76 webpages (or posts; I use these terms interchangeably in this paper) and converted them into a text document format, from which it then removed stopwords and stemmed the ones that remained. Here is an example of a comment in its webpage format:

A note to commenters: If you're here for an answer, there isn't a sufficiently good one posted yet. The thread is highly upvoted because people are interested in the question, not because there's an answer. Please refrain from posting about your personal experiences with or attitudes towards gay men and their speech, or how gay men in your country/region talk. If you have substantive comments to make that have a strong basis in scientific research, or research articles to share, go ahead.

Finally, commenters whose sole contribution here is to ask "what happened?" are likely to find themselves banned. If you want to know, see /u/millionsofcats' post below.

Here is that same comment after the process of removing stopwords and stemming:

note comment re answer isn suffici good one post yet thread highli upvot peopl interest question answer pleas refrain post person experi attitud toward gay men speech gay men countri region talk substant comment make strong basi scientif research research articl share go ahead final comment whose sole contribut ask happen like find ban want know see $u$ millionsofcat post

The corpus consisted of approximately 1,175,000 words. After removing stopwords and stemming, this total was reduced to approximately 303,000 words. The stopped and stemmed documents contained an average of 15,000 words each, and ranged from approximately 7,000 to 20,000 words each. 


\subsubsection{Data Analysis}

In the next phase, I put the resulting corpus of text into the topic modeling website created by Mimno (2018). (Hereafter, this website will be referred to by its title "jsLDA," which stands for latent Dirichlet allocation in Javascript.) I uploaded the Reddit texts and included additional stopwords to further refine the results (e.g. I excluded the words "gay" and "sound;" we would expect these words to be present due to the initial search, so having them turn up in the topics list keywords did not provide useful information). Then, I set the number of topics to 10 . The number of topics specifies the number of latent variables the model should derive from the corpus (see §3.1.1). I tested the script set at 5, 10, and 20 topics. The results obtained with the script set to ten topics produced the least ambiguous results and thus this data set was used in the present research. Lastly, I ran 1000 iterations (i.e. the algorithm passed through the dataset 1000 times). The minimum number is 50 , but I ran the extra iterations to give the model more chances to produce an optimal summary of the corpus.

jsLDA produces a list of topics, each comprised of a topic identification (ID) number and a string of keywords that reflect the content of that category. The order in which topics appear on the list is not significant (i.e. the first topic in the series is not highest or most important; the ordering does not matter). The website also provides a table of values expressing how related each document is to each topic. This table gives information about which documents are most strongly associated with each topic and thus are most likely to reflect what a given topic is about. In topic modeling, these are referred to as "top documents" (as mentioned in §3.1.1). However, hereafter in this paper I will 
refer to them as "top posts." I call them "top posts" instead because after the topics list was generated, I was no longer interacting with the document form of each post (i.e. the comments of the webpage, extracted into a text file, with stopwords removed and remaining words stemmed). Thus, "top posts" better summarizes the form of the text that I was interacting with. Both the list of keywords in the topics list and the top 5 posts most strongly associated with each topic were used in the process of intuiting what each was trying to express about the themes of the corpus.

In the current study, jsLDA generated a list of 10 topics comprised of 10 associated keywords each. See Table 3.3 for the topics list generated for this project. The first column contains the topic ID number, and the second shows the top 10 most frequently co-occurring keywords. Bolded topics are those that will be examined in this study using discourse analysis. See Appendix B for a version of the topics list with the top 5 posts that are most strongly associated with each listed beside the keywords.

To interpret the resulting topics list, I compared the keywords associated with each to one another. Next, I visited the five webpages most strongly associated with each topic (i.e. top 5 posts) and skimmed the comments contained therein. I took notes on what I thought the topics were trying to encapsulate. Based on this information, I grouped similar topics together and assigned them a summarizing label that I am calling the themes of the corpus. This process resulted in 5 themes across the 10 topics, which are described $\$ 4.1$. 
Table 3.3

Topics List for 'gay voice' and 'sound* gay' across 76 Reddit Posts

\begin{tabular}{|l|l|}
\hline $\begin{array}{l}\text { Topic } \\
\text { ID \# }\end{array}$ & \multicolumn{1}{c|}{ Keywords } \\
\hline 0 & men straight sexual women social sex lesbian woman true sens \\
\hline 1 & com http vocaroo fuck youtub video thank delet fire brand \\
\hline $\mathbf{2}$ & speak lisp speech men cultur homosexu languag feminin differ pattern \\
\hline 3 & talk friend straight stereotyp normal act person notic girl ask \\
\hline 4 & accent http com www reddit comment org southern read american \\
\hline 5 & feel fuck life love live hate someth never right find \\
\hline $\mathbf{6}$ & tri chang someon speak tell high pitch feminin probabl good \\
\hline 7 & still actual pretti point alway reason call put person work \\
\hline 8 & question post remov ask anyth simpli edit act delet genet \\
\hline 9 & record hear frequenc head differ ear http pitch sing deeper \\
\hline
\end{tabular}

For the purposes of discourse analysis, I focus on Topic 2 and Topic 6 . Both topics contain the root "feminin" in their list of top 10 keywords, which makes them good candidates to explore the ideological links between gay-sounding voices and femininity on Reddit. I also chose to focus on two topics to limit the amount of data under review for this project.

To sample a feasible amount of text to look at more closely for how these terms function in context, I chose a single excerpt from each of the top 5 posts for both Topic 2 and Topic 6. Excerpts were selected if they contained the root "feminin" (preferably multiple times) and if they began with a comment that was replying to the original poster (i.e. one that begins in the leftmost position). Moreover, I gave preference to sections of the texts that demonstrated some interaction between users. I tried to select excerpts 
where users engaged (at least somewhat) with the content of the comment that began the sub-conversation. Put another way, I aimed to select dialogic conversations within the post as opposed to a sequence of monologic one-to-many posts (Thorne \& Ivković, 2015, p. 172). This process resulted in 10 excerpts consisting of 4638 words overall: 2829 words from Topic 2 excerpts, 1809 from Topic 6 excerpts. (Average length $=463.8$ words; Median $=363 ;$ Minimum $=172 ;$ Maximum $=1165$. A copy of these excerpts can be found in Appendix C.

Within these excerpts, I sub-sampled further to find sentences for transitivity analysis (see §3.3.1). I selected all sentences that contained the root "femin" (shortened from the root "feminin" in the topics list to include the word "effeminate"). This process resulted in 44 sentences for analysis (872 words total). I extracted 22 sentences across 15 comments by 13 users (none of which were repeated across excerpts) from Topic 2 excerpts. These sentences were further broken down into 37 clauses for transitivity analysis. I extracted an additional 22 sentences across 14 comments by 11 users from Topic 2 excerpts. (There was one user who is represented twice across top posts.) These sentences were further broken down into 38 clauses for transitivity analysis. The sentences from Topic 2 contained 65 total verbs to be coded and the sentences from Topic 6 had 71 total verbs to be coded. The findings from this process are presented in $\S 4.3$.

Lastly, I replaced the sentences coded for transitivity analysis back into their original context in the excerpts to determine which tactics of intersubjectivity were present in these interactions. I read over each of these excerpts multiple times and took 
notes about which tactic was present and how it was combined with other tactics to arrive at the findings that I present in $\$ 4.4$.

\subsection{Overview}

Since I presented a lot of information in this chapter, let me briefly review the entire process in informal language and in bullet-point format. Also, see Figure 3.2 for definitions of four words that I use frequently in this thesis (post, document, topic, theme) with pictures.

- A Python script retrieved the first 100 search results from Google, then reduced this number to 76 (for math reasons). ( 1,175,000 words)

○ The Python script converted these 76 webpages into 76 text documents.

○ Then, it removed commonly-used non-content words, and reduced different forms of the same root word to a single form.

- Now I had my corpus of prepared text to run topic modeling on. ( 303,000 words)

- I uploaded the corpus onto jsLDA, which ran topic modeling on all of the documents. I removed some additional words, and had jsLDA pass the documents through the algorithm 1000 times to ensure strong results.

○ jsLDA produced a list of 10 topics, composed of keywords that were frequently co-occurring with one another in the documents that make up the corpus. It also provided me with a spreadsheet telling me how strongly 
each document was associated with each topic. I focused on the top 5 for each topic.

- I examined the keywords that comprised each topic. I also visited the webpage form of all 50 documents, and skimmed the comments on them.

- Based on this process, I assigned summarizing labels to capture the main themes I was seeing. I determined that 5 themes best summarized the webpages in this corpus.

- I decided to focus on Topic 2 and Topic 6 , because they both contained the root "feminin" but were categorized under different themes. I wanted to know more about the discourses that linked sounding gay with sounding feminine on these Reddit posts.

- I selected excerpts from the top 5 posts associated with Topic 2 and Topic 6 to reduce the amount of data that I would examine through discourse analysis (transitivity analysis and tactics of intersubjectivity analysis).

- I chose interactions on these posts that contained the word "feminine" (or some variation of it, like effeminate or feminization). I also tried to pick comments where users were interacting with one another.

- This process reduced the amount of data I was looking at to 4638 words across 10 excerpts.

- Within these excerpts, I extracted 44 sentences ( 872 words) to examine in the transitivity analysis.

- I coded the 44 sentences using the labels provided by transitivity analysis. 
- I placed these coded sentences back into the excerpts. Then I read over all 10 excerpts and took notes about which tactics of intersubjectivity I saw in them.

The following chapter describes the results of this process. 

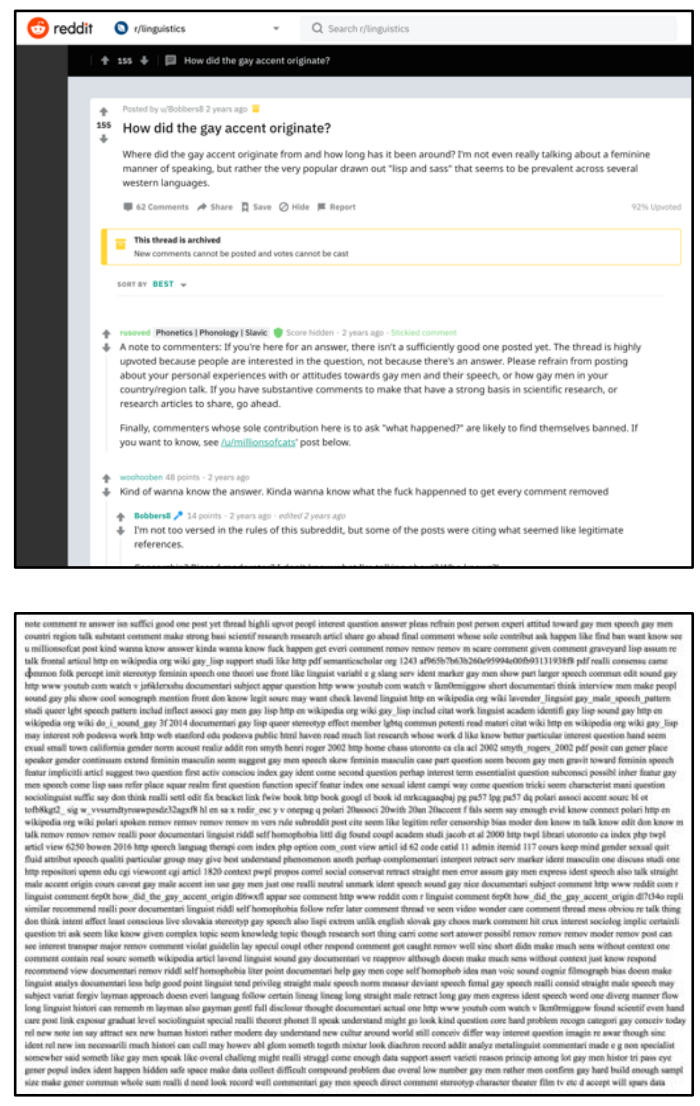

\begin{tabular}{|l|l|}
\hline $\begin{array}{l}\text { Topic } \\
\text { ID \# }\end{array}$ & \multicolumn{1}{c|}{ Keywords } \\
\hline 0 & men straight sexual women social sex lesbian woman true sens \\
1 & com http vocaroo fuck youtub video thank delet fire brand \\
\hline 2 & speak lisp speech men cultur homosexu languag feminin differ pattern \\
3 & talk friend straight stereotyp normal act person notic girl ask \\
\hline 4 & accent http com www reddit comment org southern read american \\
\hline 5 & feel fuck life love live hate someth never right find \\
\hline 6 & tri chang someon speak tell high pitch feminin probabl good \\
7 & still actual pretti point alway reason call put person work \\
\hline 8 & question post remov ask anyth simpli edit act delet genet \\
9 & record hear frequenc head differ ear http pitch sing deeper \\
\hline
\end{tabular}

\begin{tabular}{|c|c|c|}
\hline Themes & $\begin{array}{l}\text { Topic } \\
\text { ID \# }\end{array}$ & Keywords \\
\hline \multirow{2}{*}{$\begin{array}{l}\text { Internalized } \\
\text { homophobia }\end{array}$} & 5 & feel fuck life love live hate someth never right find \\
\hline & 6 & tri chang someon speak tell high pitch feminin probabl good \\
\hline \multirow{2}{*}{$\begin{array}{l}\text { Cross-linguistic } \\
\text { distribution }\end{array}$} & 2 & speak lisp speech men cultur homosexu languag feminin differ pattern \\
\hline & 4 & aceent http com www reddit comment org southern read american \\
\hline \multirow{3}{*}{ Origins } & 0 & men straight sexual women social sex lesbian woman true sens \\
\hline & 3 & talk friend straight stereotyp normal act person notic girl ask \\
\hline & 8 & question post remov ask anyth simpli edit act delet genet \\
\hline $\begin{array}{l}\text { Hearing one's } \\
\text { voice recorded }\end{array}$ & 9 & record hear frequene head differ ear http pitch sing deeper \\
\hline Pop culture / & 1 & com http vocaroo fuck youtub video thank delet fire brand \\
\hline Miscellaneous & 7 & still actual pretti point alway reason call put person work \\
\hline
\end{tabular}

Figure 3.2. A visual glossary of terms that are used frequently in this thesis.
Post: a webpage containing a main question or topic posted by a user with comments in response from the community.

The Python script retrieved the URLs corresponding to the first 100 Reddit posts containing the search terms, but then reduced this number to 76 (since posts with less than 1000 words were eliminated). Therefore, there are 76 webpages represented by this corpus, totaling around $1,175,000$ words.

Document: the comments from the post/webpage, extracted into a text file, with stopwords removed and remaining words stemmed.

There are 76 documents in this corpus, totaling around 303,000 words.

Topic: a "recurring clusters of co-occurring words" (Törnberg and Törnberg, 2016, p. 405).

Each row in this table is a topic; there are 10 total.

Theme: a summarizing label that I determined based on a review of the keywords and top posts associated with each topic. (See section 4.1.)

Each row in the leftmost column is a theme; there are 5 total. 


\section{Chapter 4: Results}

I start this chapter with an explanation of the main themes found in the corpus of Reddit posts. Next, I list the acoustic features that users mention as characteristic of a gay-sounding voice, followed by a description of the subreddits that the excerpts are found on. After this, I share the results of the transitivity analysis with a focus on the most frequently occurring process types. I finish the chapter by highlighting notable trends in the tactics of intersubjectivity analysis.

\subsection{Main Themes in Corpus}

I determined that the following five themes best summarize the Reddit posts in this corpus:

1. Internalized homophobia

2. Cross-linguistic distribution

3. Origins

4. Hearing one's voice recorded

5. Pop culture / Miscellaneous

See Table 4.1 for a visual representation of how these themes map on to the list of topics presented in $\$ 3.2 .3$. 
Table 4.1

Topics List Arranged by Main Themes in Corpus

\begin{tabular}{|l|l|l|}
\hline Themes & $\begin{array}{l}\text { Topic } \\
\text { ID \# }\end{array}$ & \\
\hline $\begin{array}{l}\text { Internalized } \\
\text { homophobia }\end{array}$ & 5 & feel fuck life love live hate someth never right find \\
\hline $\begin{array}{l}\text { Cross-linguistic } \\
\text { distribution }\end{array}$ & $\begin{array}{l}6 \\
\text { tri chang someon speak tell high pitch feminin probabl good }\end{array}$ \\
\hline Origins & 4 & speak lisp speech men cultur homosexu languag feminin differ pattern \\
\hline $\begin{array}{l}\text { accent http com www reddit comment org southern read american } \\
\text { Hearing one's voice } \\
\text { recorded }\end{array}$ & 9 & men straight sexual women social sex lesbian woman true sens \\
\hline $\begin{array}{l}\text { Pop culture / } \\
\text { Miscellaneous }\end{array}$ & 1 & talk friend straight stereotyp normal act person notic girl ask \\
\hline \begin{tabular}{l} 
question post remov ask anyth simpli edit act delet genet \\
\hline
\end{tabular} & 7 & still actual pretti point alway reason call put person work \\
\hline
\end{tabular}

The first theme, internalized homophobia, represents posts and comments in which users to discuss not liking their gay-sounding voice and looking for advice on how change it to conform more closely with normative ideals. Keywords such as chang (the stemmed form of "change") support this interpretation. Posts in this theme tend to come from subreddits for segments of the LGBTQ+ community such as r/askgaybros and $\mathrm{r} / \mathrm{ftm}$. Emotion-related keywords (e.g.feel, love, hate) reflect the socially-oriented nature of these posts: users share opinions or poll peers on theirs and request advice. For example, a deleted user in $\mathrm{r} / \mathrm{ftm}$ (a subreddit for trans men) asks in their post description:

does anyone know how to not have "gay voice" when your voice drops? Please do not be offended, but I know a lot of guys on t [i.e. testosterone] who sound like stereotypical gay men once they start $t$. 
I think its the intonation. Im a straight guy and $i$ dont want other dudes calling me gay because of my voice. Is there anything $\mathrm{i}$ can do to change how i speak? I have a "feminine" voice and my intonation is also feminine.

Posts in this theme also discuss the sociosexual capital of having a "gay voice." Users talk about their preferences about how their partners' voices sound. For example, in a post entitled "Is "gay-voice" a turn on to anyone?", user getthelumpout notes in the post description:

For a while now, though, I've actually been seriously turned on with guys I'm attracted to having the quote-unquote "gay voice." I'm not talking about the overly dramatic, snapping, "yas queen," over the top voice (not that there's anything wrong with that. And that's mostly mannerism, anyway.) Just--when you hear a guy talk, and there's no question he's gay.

Thus, some users find a gay-sounding voice to be attractive. Other users do not, such as a deleted user whose post begins with: "Is the stereotypical gay voice an instant turn-off for you? I feel really shallow for thinking like this but I can't help it.” In a comment responding to this original post, user startingover90 writes: "It's not an issue either way for me, I don't internalize homophobia." As this interaction demonstrates, many users express a disapproval of gay-sounding voices, but there are also people on Reddit who disagree and are pushing back against the notion that sounding gay is undesirable and should be changed.

The second theme, cross-linguistic distribution, refers to posts and comments in which users discuss if sounding gay is a phenomenon in languages besides English. It also includes posts where users ask if a person who has a gay-sounding voice in English 
will also be read as gay while speaking a foreign language. Keywords such as language, accent, and cultur support this interpretation. Posts included in this theme tend to be found on subreddits such as r/NoStupidQuestions that follow a question-and-answer (Q\&A) format: the original poster inquires about something, and users who reply to that post are expected to provide thorough answers. Some of these Q\&A subreddits are academic in nature, such as $\mathrm{r} /$ AskSocialScience and $\mathrm{r} /$ linguistics. A representative example of this theme can be found on r/NoStupidQuestions where the original poster asks: "Are homosexuals in non-english speaking countries knowing for having a 'gaylisp'?" User cabr1 to replies by stating:

So... the stereotypically "gay" speech pattern is derived entirely on 1) degree of cultural presentation of gender 2) individual identification as masculine/feminine 3) phonology of the language in question.

So it wouldn't always be a lisp, and it wouldn't always apply to one person versus the next. But yes, there's always a way for someone to signal their queerness one way or another. If they so choose.

As this comment reflects, interactions within this theme often involve discussions of phonetics/phonology of non-English languages and gender presentation across cultural lines.

The third theme, origins, represents posts in which users talk about why and how an individual comes to sound gay. Keywords such as genet (the stemmed form of "genetic") hint at one of the main questions discussed in this theme: the developmental trajectory of acquiring a gay-sounding voice. Users ask whether gay voices are pre- 
determined biologically, a result of socialization, or intentionally performed. For example, in a post in r/NoStupidQuestions entitled "Why do a lot of homosexuals have that 'gay voice?", a deleted user writes: "Something I should point out is that this doesn't have a biological, objective basis, because people who have this voice are known to lose it when going under anesthesia during medical operations. It's learned/cultural.” User nmham responds by asking: "You have a source for that claim? I've known lots of people who had the voice long before they came out and were involved in gay culture." Another aspect of this theme is an interest in the diachronic trajectory of gay-sounding voices. For example, user Bobbers 8 created a post on r/linguistics entitled "How did the gay accent originate?" In response to other users' answers about the production of $/ \mathrm{s} /$, Bobbers8 requests clarification:

Forgive my layman approach to this, but doesn't every language follow a certain lineage?

In this lineage, how long has the straight male retracted /s/? How long have gay men expressed their identity through speech?

In other words, did one diverge from the other? Or have both manners flowed down as long as linguistic history can remember?

Users on posts in this theme seek to discover when a distinctly gay-sounding voice came to be and when it was first attested. Posts included in this theme tend to be found on subreddits that follow a question-and-answer format (i.e. the original poster inquires about something, and users who reply to that post are expected to offer an answer to that 
question), such as r/AskReddit. Some of these Q\&A subreddits have an academic orientation, such as $\mathrm{r} /$ AskHistorians and $\mathrm{r} /$ linguistics. The similarity in types of subreddits that comprise the cross-linguistic distribution and origin themes, as well as two shared top posts (see Appendix B), suggest that there is some overlap between them. These two themes are less distinct from one another when compared to the other three that I delineate in this section.

The fourth theme reflects conversations about sounding gay specifically within the context of hearing a recording of one's own voice. It refers to posts and comments in which users are discussing how their voice sounds different to their own ears as compared to when they hear it played back to them in a recording. Keywords such as record, hear, frequenc, head, and ear support this interpretation. The top posts associated with this theme are found on subreddits such as r/askscience and $\mathrm{r} /$ todayilearned, and are not discussing gay-sounding voices directly. For example, one post title on r/todayilearned states:

TIL [today I learned] the reason why we hate the recorded sound of our voice is because our skull changes the resonance of our voice from within and creates more bass. When we hear a digital recording of our voice, although slightly unfamiliar to ourselves, it's exactly how other people hear it.

Three users on that post engage dialogic interaction with each other about sounding gay:

option_i: I sound gay, I mean, I am gay, but...I'm embarrassed by it.

levi_biff: I have this exact problem. And this semester I took a class over audio drama where we got to make our own podcasts/radio 
shows. In my head I don't sound THAT gay, but everytime I heard myself on a recording I thought Westborough Baptist was about to show and protest me.

StarCraft_SpaceQuest: Ha! Same here. You don't know how emasculated you can sound as a man until you record yourself talking.

Users on these posts converse about their reactions to hearing an audio recording of their own speech, and comments where people are saying that they find themselves to sound gay are a subset embedded within the more general conversations.

The fifth and final theme encompasses an assortment of posts that do not fit neatly into the other categories. Interactions tend to focus on sounding gay in relation to a comedic photo included by the original poster on subreddits such as r/funny. This theme also includes conversations where users discuss whether or not a figure in pop culture (fictional or real) sounds gay or can be assumed to be gay based on their voice. For example, at least two posts in this theme consist of users discussing whether a character in a video game is supposed be legible as gay: both based on acoustic features in their speech, and the content of their and other character's utterances. Another example comes from the subreddit r/NBA (as in National Basketball Association), where the original poster asks: "Why does [basketball player and analyst] Richard Jefferson sound like an egg when he talks? His voice is really strange, like I wouldn't expect it to come out of him. Anyone else notice this?" User imadogg replies: "Race is half of it, him sounding sorta gay is the other half." This comment prompts a dialogic interaction, shown in Figure 4.1: 


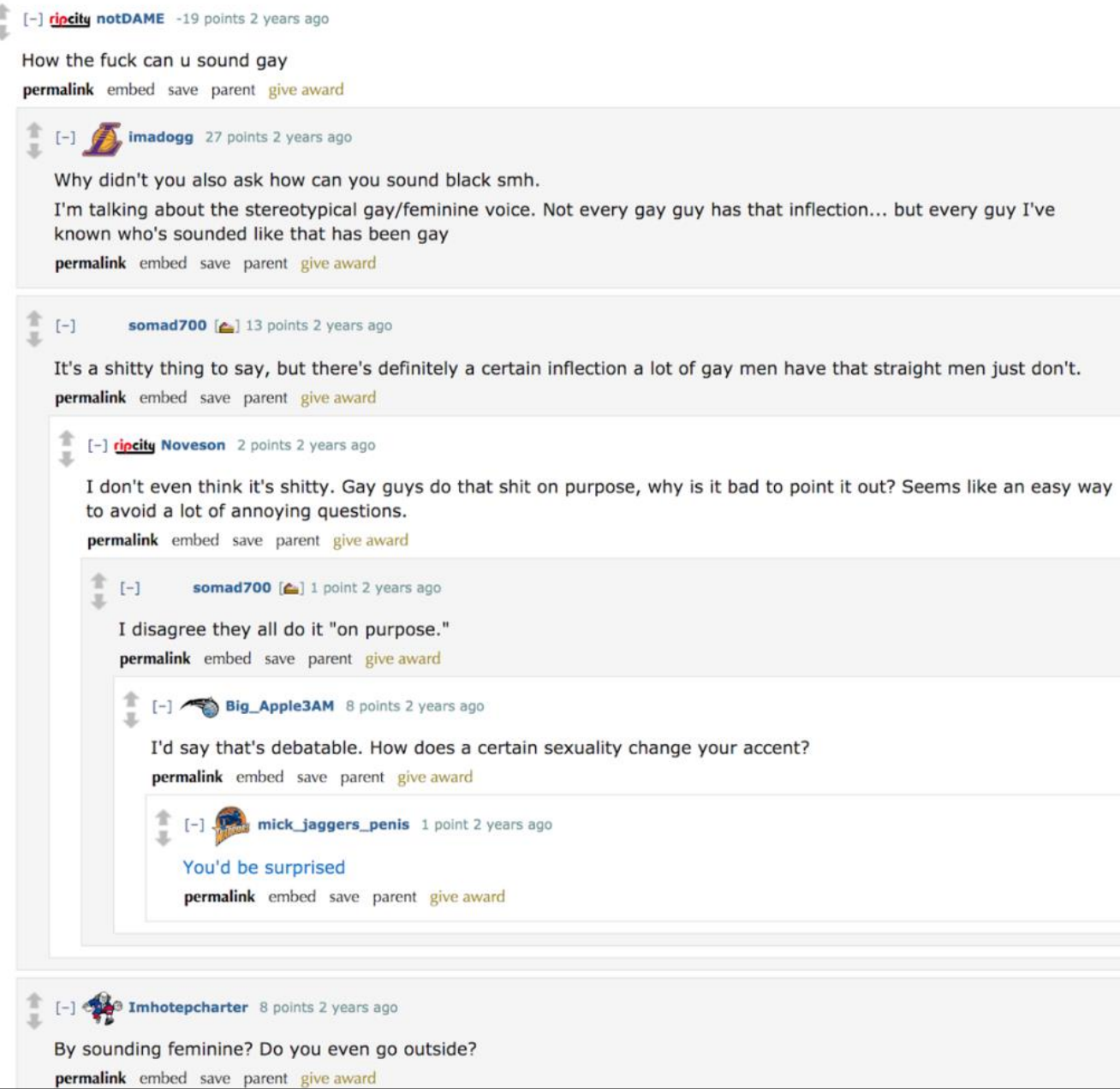

Figure 4.1. An example of interaction that represents theme 5 (pop culture / miscellaneous) found on the subreddit $\mathrm{r} / \mathrm{NBA}$.

Note that the comment "You'd be surprised" is a hyperlink that connects to a trailer for the documentary Do I Sound Gay? on YouTube. The interaction in Figure 4.1 demonstrates a final point about this theme. Although it is more varied in terms of the posts it includes, the interactions found here still raise important points related to the concept of gay-sounding voices, such as the premise that one's voice can indicate their sexuality and the ideological links between sounding gay and femininity. 
I want to conclude this section with a brief summary about other trends in the corpus overall. First, the majority of the posts in this corpus focus on gay male voices. There is one document out of 76 that asks "Is there a lesbian voice?" In contrast, over one-third of the titles of documents in this corpus refer specifically to gay men. A closer examination of all of the posts and their comments would likely reveal this rate to be much higher. Second, most of the excerpts I looked at do not mention factors such as race, geographic location, income level, or any other potentially salient social demographic factors. (The interaction in Figure 4.1 above is one of the few exceptions.) Therefore, in the remainder of this paper where I talk about how Reddit users discuss "gay voice," remember that these conversations largely focus on the voices of cis white gay men unless otherwise noted, such as in the conversations found on the subreddit $\mathrm{r} / \mathrm{ftm}$ (see $\$ 4.4 .2$ below).

4.2 Context for the Discourse Analysis

4.2.1 What acoustic features do Reddit users in these excerpts associate with a "gaysounding" voice?

Before proceeding with my analysis, it is important to take a moment to clarify what linguistic features that Reddit users associate with a gay-sounding voice in these excerpts. The first clue to how users define "gay voice" comes from the keywords found in the topics list. The keywords for Topic 2 include "lisp," the misnomer used to describe 
a fronted /s/. The keyword "pitch" appears in the list for Topic 6 . A closer examination of the excerpts confirms these trends. In Topic 2, users most often refer to the fronted /s/ when characterizing a "gay voice," although suprasegmentals such as pitch ("sounds like a guy trying to imitate a typical estrogen charged female"), volume ("loud"), and intonation ("vocal inflection;" "the 'singy' way of speaking") are also used. Interestingly, users in the excerpts from Topic 6 do not mention fronted /s/. In one interaction, users refer to phonetic duration ("they extended their words;" "I elongate some words"). Otherwise, they predominantly focus on suprasegmental features such as pitch ("how their voice goes up a few octaves"), pitch variation ("raise the pitch of their voice up and down during sentences"), rhythm, and intonation. Specifically, high rising terminals are listed as a characterizing feature across two excerpts (e.g. "So like everything . . . sounds like a question?"). However, it is not uncommon to find conversations that proceed without a need to explicitly define what they are talking about. There appears to be an assumption that it is a given that other users know what they are talking about when they mention gay voice or sounding gay.

\subsubsection{Which subreddits are these excerpts found on?}

To give some context to the analysis that follows, I think it is important to describe in more detail the subreddits that the excerpts I selected are found on. As a reminder, a subreddit is a community within Reddit focused around a subject or theme. Each subreddit has its own rules that govern conduct within it, and Reddit users who act 
as moderators of the content. (A full list of subreddits represented in this corpus can be found in Appendix D.)

In Topic 2, two of the excerpts (\#1, \#3) come from r/NoStupidQuestions (approximately 1,275,000 members, 24 moderators, a community for 6 years), the tagline of which is: "There is no such thing as a Stupid Question!" (NoStupidQuestions, n.d.). The description of this subreddit characterizes it as a place to ask (sincere) questions on any matter that a user is curious about but might be self-conscious to ask about otherwise. Ingenuine or medical-related questions are not allowed, and users are encouraged to search for their question to see if it has been answered before. Also, users who submit a top-level comment (those that reply directly to the original poster) are "must contain a genuine attempt at an answer" (NoStupidQuestions, n.d.).

Another two of the excerpts from Topic $2(\# 4, \# 5)$ come from r/linguistics (approximately 174,000 members, 9 moderators, a community for 11 years). As the title of the subreddit suggests, it is a forum for any user to ask questions related to the scientific study of language, in which other users who are familiar with linguistics are encouraged to reply to with comprehensive answers supported by academic sources (especially those which are open to the public). Moderators tend to delete questions that are based on prescriptivism (i.e. "asking whether some usage is 'correct"'), inappropriate, asked with the purpose of furthering a political/religious agenda, or more well-suited to another language-related subreddit (e.g. translation, etymology, homework help) (Linguistics, n.d.). Replies that are based on anecdotes and speculation, or that are facetious in nature, are also removed by moderators. 
Relatedly, the second excerpt from Topic 2 comes from the subreddit r/AskSocialScience (approximately 87,000 members, 15 moderators, a community for 8 years). Like with r/linguistics, any Reddit user can ask a "novel and specific and answerable" question within the purview of disciplines who study society and the interpersonal relationships that constitute it (AskSocialScience, n.d.). Users who have a background in one of the social sciences are encouraged to provide thorough answers supported by academic citations. The rules on this subreddit are similar to those mentioned earlier in this paragraph.

In Topic 6 , two of the excerpts (\#1,\#3) come from r/ftm (approximately 59,000 members, 6 moderators, a community for 7 years), the description of which is: "Supportbased discussion place focused on trans men, trans-masc individuals, and other people assigned female at birth who are trans" (Ftm, n.d.). This subreddit is a forum for users to share information and ask questions related to subjects such as masculinizing surgeries and trans-oriented products such as binders and prosthetics. It is also a social space for users to ask for support or advice, as well as share memes, rants, and celebrations. Rules center around maintaining a civil environment through respecting individual differences, avoiding body shaming, and only speaking from one's own experiences. The rules also prohibit users from posting photos/information about anyone but themselves and using the space for advertisements. All contributors are also required to use "flairs" (or icons next to posts) that identify the genre of their content.

In Topic 6 , three of the excerpts ( $\# 2, \# 4, \# 5)$ come from the subreddit r/askgaybros (approximately 173,000 members, 1 moderator, a community for 6 years), 
the tagline of which is: "This is where you can ask the manly men for their opinions on various topics" (Askgaybros, n.d.). Compared to the previous subreddits described, this one has relatively few moderator-enforced rules (the main exceptions being sharing people's private information and illegal content). Users are instead encouraged to use the voting system built into Reddit to regulate its content. Posts can come in many forms, including questions, statements, and calls for advice (the latter two of which are marked with flairs that label them as such). Skimming the titles in this subreddit indicates that much of the content is related to gay male sexual interactions and social concerns (e.g. coming out), but there are also posts unrelated to either of these subjects (e.g. advice on skin care).

\subsection{Transitivity Analysis Findings}

Two people (myself and my committee chair) each coded the full data set of 44 sentences. The initial rate of agreement was $88 \%$, and differences were negotiated until this rate reached 100\%.2 Data examples in this section are formatted as such: Comment text from Reddit (Username; Topic \#, Excerpt \#, Subreddit title).

In the sentences extracted from Topic 2, mental processes make up the highest proportion of coded verbs (30.77\%). The second most frequently-occurring type of process is identifying intensive (23.08\%), followed by material (18.46\%). Altogether, these types account for $72.31 \%$ of all verbs coded for this topic. The sentences extracted 
from top post texts for Topic 6 consist most highly of mental processes (29.58\%),

followed by material (26.76\%) and then attributive intensive (15.49\%). Altogether, these process types account for $71.83 \%$ of all verbs coded for this topic. Table 4.2 shows the total numbers of each process type across the sentences extracted from excerpts from the top 5 documents of Topic 2 and Topic 6.

Table 4.2

Process Type Totals by Topic

(Percentage of total is listed first, followed by the raw count of tokens in parentheses. Bolded rows are those that are focused on in this paper.)

\begin{tabular}{|l|l|l|}
\hline Process Type & Topic 2 & Topic 6 \\
\hline Material & $\begin{array}{l}\mathbf{1 8 . 4 6 \%} \\
\mathbf{( 1 2 )}\end{array}$ & $\begin{array}{l}\mathbf{2 6 . 7 6 \%} \\
\mathbf{( 1 9 )}\end{array}$ \\
\hline Mental & $\begin{array}{l}\mathbf{3 0 . 7 7 \%} \\
\mathbf{( 2 0 )}\end{array}$ & $\begin{array}{l}\mathbf{2 9 . 5 8 \%} \\
\mathbf{( 2 1 )}\end{array}$ \\
\hline Verbal & $1.54 \%$ & $5.63 \%$ \\
& $(1)$ & $(4)$ \\
\hline Behavioral & $6.15 \%$ & $2.82 \%$ \\
\hline Existential & $(4)$ & $(2)$ \\
\hline Identifying Intensive & $9.23 \%$ & $4.23 \%$ \\
& $(6)$ & $(3)$ \\
\hline Attributive Intensive & $\mathbf{2 3 . 0 8 \%}$ & $\mathbf{7 . 0 4 \%}$ \\
& $\mathbf{6 . 1 5 \%}$ & $\mathbf{( 5 )}$ \\
\hline Possessive & $\mathbf{1 5 . 4 9 \%}$ \\
\hline Causative & $3.08 \%$ & $\mathbf{( 1 1 )}$ \\
\hline Total & $(2)$ & $(3)$ \\
\hline & $1.54 \%$ & $4.23 \%$ \\
& $(1)$ & $(3)$ \\
\hline & $100 \%(65)$ & $100 \%(71)$ \\
\hline
\end{tabular}


Mental process verbs (coded as "Pme") occur most frequently across both topics. This finding confirms that these conversations center around what people think, feel, and know. Users are discussing their own and others' perceptions (e.g. consider, find, hate, love, notice, own, think, tell [as in determine]). For example,

I think (Pme) you would find (Pme) it to be a more common speech pattern in effeminate gay men. [missinfidel; T2, E2, r/AskSocialScience]

I'd much rather fuck a guy who owns (Pme) his feminine side/voice than one who is "straight acting" because he hates (Pme) himself for being a big ol' queer. [startingover90; T6, E5, r/askgaybros]

This finding also logically follows given that I coded the verb 'to sound' (as in "x sounds $y$ [to me]") as a mental process. One of the phrases that was searched for to build this corpus was "sound* gay," so it is not surprising to find this verb in the excerpts. I coded the verb 'to sound' as a mental process when used in this way because users are describing what they think about a phenomenon, even if the senser (the person making this judgement) is often omitted. If the verb 'to sound' were used in a construction such as, "The alarm sounds every morning at 5am," I would likely code it as a material verb, since it refers to an event in the outside world that is perceptible by a variety of people. Instead, when people are talking about how a person 'sounds feminine,' they are expressing their mental judgement about a stimuli, a process that occurs in their inner world. Here are two examples of sentences from the excerpts that demonstrate this pattern:

It just sounds (Pme) slightly more effeminate. (Flater420; T2, E3, r/NoStupidQuestions) 
Just sounding (Pme) feminine is not enough to make it sound (Pme) "stereotypically gay" to me anymore. [Andrew985; T6, E4, r/askgaybros]

There are 2 tokens of 'to sound' in Topic 2 (10\% of mental process verbs in T2), and 7 tokens in Topic 6 (33\% of mental process verbs in T6).

The high frequency of material processes across topics also makes sense. Material verbs (coded as "Pm") represent actions and events that happen in the outer world which are tangible to multiple participants. Many of these verbs are related to speech since I am searching texts where people are discussing voices (e.g. elongate [words], lower [one's pitch], pronounce, retract [/s/], speak, talk). For example,

Mostly what people notice about gay speech, and specifically a stereotypical gay accent are things that make people sound feminine overall, such as the way people pronounce $(\mathbf{P m}) / \mathrm{s} /$, or certain word choices. [pyry; T2, E4, r/linguistics]

My voice isn't a fem tone but I elongate ( $\mathbf{P m})$ some words and I don't even notice it until someone mocks (Pm) my voice. [guyasking; T6, E5, r/askgaybros]

As these examples also demonstrate, the difference in rates (18.46\% in T2 versus $26.76 \%$ in T6) has to do with the fact that, in Topic 2, users are discussing "gay voice" in a theoretical manner (i.e. Where did it come from? Is it found in other languages?). In Topic 6, users are discussing it in practice: they discuss their own or potential dating partners' voices. Therefore, the higher rate of material processes in Topic 6 reflects the interpersonal focus of these conversations (e.g. appease, fuck, hide, meet, mimic, mock).

The most interesting finding from this analysis is that both topics have an intensive process (coded as "Pi") in their top 3 most frequently-attested process types, but 
which kind of intensive process is different across the two. Identifying intensive verbs state that two things exist in relation to one another: one participant, the value (coded as "V") "serves to define the identity" of the other participant, the token (coded as "T") (Eggins, 2008, p. 241). Identifying intensives make up $23.08 \%$ of the total process types for Topic 2 but only $6.15 \%$ of Topic 6 . Attributive intensive verbs also state that two things exist in relation to one another, but in contrast with the previous type, "a quality, classification or descriptive epithet (an attribute, coded as "At") is assigned to a participant" called the carrier (coded as "Cr") (Eggins, 2008, p. 239). Attributive intensives account for $15.49 \%$ of the verbs in Topic 6 (but only $7.04 \%$ of Topic 2).

The trend that emerges from the data is that users in the Topic 2 excerpts delineate their points in order to be able to say something about the conceptual questions being posed. For example, in r/AskSocialScience, a user posted "Honest question, but what is the story with the 'gay' lisp?" In an interaction between two users about whether or not only "effeminate" gay men have a fronted /s/, one notes that:

there's no clear-cut difference between "effeminate" guys and "noneffeminate" guys. It (T) 's $(\mathbf{P i})$ a spectrum $(\mathbf{V})$, and one (T) that, in my mind, is $(\mathbf{P i})$ composed of several behaviors and characteristics including the "lisp," vocal inflection, wrist limpness, posture, excitability, interest in stereotypical "feminine" things/activities) (V). [JoanCrawford; T2, E2, r/AskSocialScience]

This finding reflects the subreddits that these excerpts are found on. These communities ask that users attempt to give comprehensive answers to the questions raised by the original poster. On the other hand, users in the excerpts from Topic 6 are communicating on subreddits that are more social in nature; the questions asked in these excerpts 
specifically are done so in the spirit of seeking advice or polling their peers. For example, the title of the second top post for Topic 6 is "I won't hook up with guys with a 'gay voice'. Does this mean I'm a bad person?” In a top level comment (one that directly responds to the question in the title), the user writes:

For me it's less about "sounding gay" (whatever that means) and more about sounding like an annoying valley girl. I don't even care if you (Cr) 're (Pi) feminine (At), it's just that particular cadence that gets on my nerves. [[deleted]; T6, E2, r/askgaybros]

Another user replies to this comment by stating:

I (Cr) 'm (Pi) a feminine gay guy (At) and I don't talk like a valley girl or a "diva". [Kai_Decadence; T6, E2, r/askgaybros]

The trend that emerges is that users in the Topic 6 excerpts focus on depicting the participants involved to exemplify their perspectives and relate those back to the title queries.

\subsection{Tactics of Intersubjectivity Analysis Findings}

Three of the tactics of intersubjectivity best frame the discourse moves being made by users in these excerpts: adequation, distinction, and denaturalization.

Adequation is the process by which "differences between [social actors] are temporarily erased or backgrounded while similarities are highlighted or emphasized" (2004a, p. 496). This move occurs when a user argues for similarity between one identity and another in making a claim. Distinction is "the ideological construction of social difference through the erasure of likeness and the highlighting of unlikeness" (2004a, p. 
496). This relationship is established when a user makes a distinction between one identity and another. Denaturalization is invoked when "claims to the inevitability or inherent rightness of identities are subverted. What is called attention to instead are the ways in which identity is crafted, fragmented, problematic or false." $(2009$, p. 24$)$. This occurs when a user declares that a given identity (or identities more generally) cannot be defined by shared attributes, or contests a given behavior or trait as a qualification to be a "real" member of an identity group.

Users across both topics utilize the tactic of adequation but do so to different ends. In Topic 2, I found that users adequate what gay men do with their voices to what straight men do with their voices, and paired this move with the tactic of denaturalization to point out that both groups (and all people) have variation in their speech that communicates their group membership(s). In Topic 6 , I found that users adequate a stereotypically gay persona with the valley girl persona and then establish a relation of distinction between those two personae and either how they speak, how they prefer their partners to speak, or how they would like to sound. These findings are summarized visually in Figure 4.2. Please note that I use singular 'they' in the following sections since Reddit users do not volunteer their pronoun preferences. 


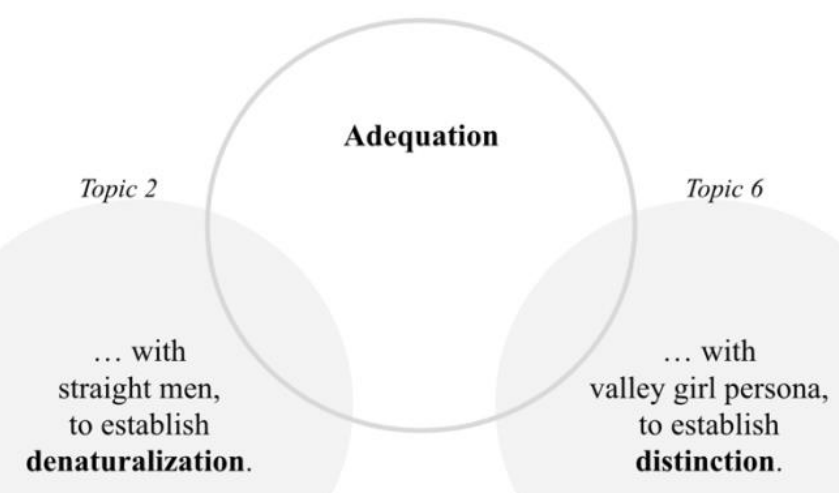

Figure 4.2. A visual summary of the tactics of intersubjectivity analysis findings.

\subsubsection{Findings from Topic 2 Excerpts}

In Topic 2, users establish an intersubjective relation of adequation between gay men and straight men, which serves to denaturalize the idea that what gay men do with their voices is unique. In r/linguistics, user Bobbers8 asks "How did the gay accent originate?" In the description, they distinguish "a feminine manner of speaking” from “the very popular drawn out 'lisp and sass' that seems to be prevalent across several western languages.” DonaNoblisPacman replies in a top level comment:

By "lisp" I assume you're talking about the frontal articulation of /s/ \{LINK: to Wikipedia page on "gay male speech"\}, supported by studies like this $\{$ LINK: to Mack \& Munson (2012)\}. There's not really consensus on "where it came from" but a common folk perception is that it imitates stereotypical "feminine" speech. One theory is that the use of fronted /s/, like other linguistic variables (e.g. slang), serves as an identity marker for gay men to show that they are 
part of a larger speech community [DonaNoblisPacman; T2, E5, r/linguistics]

This user corrects the misnomer used in the post description. They align fronted /s/ with “stereotypical 'feminine' speech," but do so cautiously, through the use of quotes around feminine, the word "stereotypical" which marks that they are referring to a generalization, and by labeling this perception as "folk." These potentially delegitimizing moves are in contrast with DonaNoblisPacman's authorization of their own opinion, indicated by their use of linguistic terms (the accurate phonetic description of fronted /s/ and the term "speech community") and academic lexemes more generally (e.g. variable, theory), as well as the inclusion of citations to support their claims. In a nested comment, user millionsofcats (a moderator of the linguistics subreddit) responds to the claim that fronted /s/ acts as an "identity marker":

There is another (or perhaps, complementary) interpretation: A retracted /s/ serves as a marker of identity--a masculine one. This is discussed in studies such as this one \{LINK: to Podesva \& Van Hofwegen (2014)\}, which propose a correlation between social conservatism and /s/ retraction in straight men.

That is, it's an error to assume it's only gay men who express their identity through their speech; we could also talk about a "straight male accent" and its origins--of course, with the same caveats as for the "gay male accent," which isn't used by all gay men. It's just that no one really has neutral, unmarked-for-identity speech. [millionsofcats; T2, E5, r/linguistics]

Millionsofcats adequates gay men and straight men through their claims about /s/ variation: they propose that we should consider that both could be modifying it. They continue this adequation in the second section with the comment that there could also be 
a "straight male accent," then immediately denaturalize the idea by noting that such a framing comes with "caveats." We can create a label for a sociolect and try to define what that consists of, but there will always be intragroup variation. Millionsofcats returns to a move of adequation: the proposition that gay men vary their speech to mark their identity is expanded to all users of language through the comment that "no one really has neutral, unmarked-for-identity speech.”

The original poster Bobbers8 responds directly to millionsofcats in a nested comment with a series of clarifying questions. One of these is: "How long have gay men expressed their identity through speech?", to which millionsofcats replies:

Broadly speaking, as long as everyone else has been expressing their identity through speech: Since the dawn of modern human language. But if you're asking how long ago gay men were expressing a specifically gay identity through speech, that's a really complicated question. [millionsofcats; T2, E5, r/linguistics]

The phrase "as long as everyone else" is a pushback against the markedness implied by Bobbers8's question. Millionsofcats adequates the behavior of gay men with humans in general to make a claim about how language works: it provides information about our social positionalities. DonaNoblisPacman speaks directly to the issue of markedness in their follow-up response:

Good points! Linguists tend to privilege straight male speech as the norm against which to measure "deviant" speech such as female or gay speech, when really we should consider that straight male speech may itself be subject to variation. [DonaNobisPacman; T2, E5, r/linguistics] 
Asking how and why gay men are varying their speech features implies a group to whom we are comparing them to that does not. DonaNoblisPacman highlights that straight male speech is the unmarked option in conversations about gay voice and in the field of linguistics more generally. They argue that we adequte gay men and women with straight men through the idea that all social groups demonstrate variation within the group and when compared to other groups. The use of quotation marks around the word "deviant" emphasizes the point that whose speech we see as moving away from an unmarked norm is linguistically arbitrary.

In another post on r/linguistics (T2 TD4), user tripplethrendo asks "why male homosexuals have an 'accent"' and "why part of this social group adopts such a specific speaking pattern.” The user Facepuncher asks a series of follow-up questions in a top level comment of this post:

OK but what i dont understand is where the gay accent comes from to begin with. It just sounds like a guy trying to imitate a typical estrogen charged female. Did one gay guy somewhere just decide he wanted to start talking like a girl as a means to show hes gay and it just blew up around the world over time?

Is estrogen a true correlation to that kind of speech in women? Because all women don't talk like that. But then if it were linked to estrogen, then this would mean all flamboyantly gay mean would be growing breasts, and I dont see that happening.

This is why I feel its just a learned thing that gays choose to do to be less manly, but what i do not understand is that being gay has nothing to do about being less of your current gender and being more like the other one but instead its just about LIKING your same gender. Why would you as a gay man want to act more feminine when other gay men don't like females? It's like defeating the purpose of attracting a 
mate of the same sex just because they feel the need to stand out. [Facepuncher; T2, E4, r/linguistics]

Facepuncher's comments demonstrate a recursion of questions about homosexuality onto the interpretation the voies of gay men (i.e. is it linked to estrogen levels?). Their comments also reflect a gender inversion model of homosexuality, i.e. that gay men are similar to women. User pyry writes a lengthy response in a nested comment. At many points during this response, the moves of adequation and denaturalization are paired. In response to the questions related to estrogen, pyry writes:

Yes, there are similarities between gay speech and the way some girls speak, but this doesn't necessarily mean the goal is to sound like a woman, nor is it true that all gay men speak this way. [pyry; T2, E4, r/linguistics]

Pyry denaturalizes the idea that gay men talk like women. First, they provide a more accurate alternative: there are speech features that both groups share. Next, they deny the reasons for this overlap in acoustic tendencies: these similarities should not be taken to indicate that gay men are trying to emulate women's voices. Lastly, they point out that there is intragroup variation in ways that gay men speak. In response to Facepuncher's comment that gay voice is "just a learned thing that gays choose to do to be less manly," pyry writes: "Yeah, just like it's a learned thing for straight people to act the way they do." This comment adequates straight and gay people by stressing that in both groups, our behaviors are acquired through socialization. Pyry makes this point to denaturalize the idea gay men behave in a way that is forced or intentionally feminine. This user goes on to note: 
In the U.S., I think it's not just gay people who are wont to express sexuality through culture, but many many other groups, and even straight people.

So, why would gay men want to act more feminine when other gay men don't like females? There's quite a range to gender behavior, and people are many kinds of things. There are also people who like all sorts of different people, so while not all gay men act really feminine, there are gay men who both like (or are attracted to) this behavior, and those who do not. [pyry; T2, E4, r/linguistics]

Pyry adequates gay and straight people through the idea that all of us express our sexuality through culture. In the next section of the comment, they denaturalize the idea that gender (or gender inversion) determines a person's behavior through the sentence: "There's quite a range to gender behavior, and people are many kinds of things." Next, they denaturalize the idea the all gay men are attracted to either feminine or masculine partners through the sentence: "There are also people who like all sorts of different people, so while not all gay men act really feminine, there are gay men who both like (or are attracted to) this behavior, and those who do not." They proceed to write:

Just because someone's gay doesn't mean that they have to behave in a certain way, and the same is true for straight people (but people just notice it a lot less), comic book geeks, physicists, and many other things where people spend enough time together due to geographical location, or special interest. [pyry; T2, E4, r/linguistics]

This comment denaturalizes the idea that gay men behave a certain way because they are gay. Instead, they propose that we consider avoiding that essentialist idea, because as a member of any given group, we will behave in accordance with ways of being associated with membership in that group in some ways and not in others, and thus this phenomenon is not unique to gay men. 
Reddit users in these examples establish an intersubjective relation of adequation between gay men and straight men to denaturalize the assumption behind many of the questions: that what gay men do with their voices is unique. These users adequate what gay and straight men do to highlight that all speakers demonstrate variation but that we focus on gay men because they are the marked case.

\subsubsection{Findings from Topic 6 Excerpts}

In Topic 6, users establish a relation of adequation between a stereotypical gaysounding voice and the valley girl persona, which serves as an act of distinction between these two character types and either their own speech, how they want others to sound, or how they want their speech to be. D'Onofrio (2015) characterizes “the Valley Girl” as:

a popularly recognized female persona that is typically white, feminine, affluent, materialistic and superficial. Language attitudes surveys on perceptions of California both within and outside of the state show reference to a stereotyped linguistic style associated with the Valley Girl (Fought 2002; Bucholtz et al. 2007), a highly stigmatized language variety often called Valspeak (Donald et al. 2004). (p. 243)

Many linguistic studies have discussed the valley girl persona, but the only example of a scholar who has related it to gay male personae is Podesva (2011). He finds that "features of the California Vowel Shift can be used in particular gay styles ([i.e. his participant] Regan's gay “partier” persona) because ... [it] indexes 'fun' and 'laid-back' meanings that derive from stereotypical California character types (valley girl, surfer, stoner, slacker)" (pp. 10-11). By way of contrast, the users in Topic 6 excerpts link a 
stereotypical gay persona and the valley girl persona through their shared trait of being “annoying."

On the subreddit r/askgaybros, a user asks: I won't hook up with guys with a "gay voice". Does this mean I'm a bad person? In the description that accompanies the title, the original poster JustTryingToFunction equates "gay voice" with having "a feminine voice" by using the terms interchangably. A user replies to this in a top level comment by stating:

For me it's less about "sounding gay" (whatever that means) and more about sounding like an annoying valley girl. I don't even care if you're feminine, it's just that particular cadence that gets on my nerves. [[deleted]; T6, E2, r/askgaybros]

This comment denaturalizes the idea that a man can sound gay with the use of quotations around the phrase in addition to the words whatever that means in parentheses directly after. Furthermore, the user creates a distinction between being feminine and speaking like a valley girl by specifying that "a particular cadence" characterizes the latter. A nested comment that follows agrees by stating:

Yes this. There are some gay dudes that talk girly and it does not bug me because it is not moronic. It is that dumbass way of talking that annoys the shit out of me. Even when girls do it. My only friend that is a girl had a period in her life where she talked like this and it drove me nuts.

So like everything she says sounds like a question? And like you just want to throttle them? 
Even dudes with deep voices can talk like this. [IsConstantlyLying; T6, E2, r/askgaybros]

User IsConstantlyLying specifies that within ways gay men speak, some "talk girly," which means that this user is not globally equating talking while gay with speaking in a feminine manner. This user differentiates gay men who speak in a feminine manner that do not bother him, from those who do; that is to say, IsConstantlyLying views gay men with a feminine voice as a separate group from gay men who speak like a valley girl. Notably, this user characterizes the valley girl manner of speaking by including a reference to high-rising terminals (or 'uptalk'): ('So like everything she says sounds like a question? And like you just want to throttle them?") The use of "like" as a discourse marker is this example (noted in bold font) invokes the valley girl persona further by utilizing an iconic feature associated with it (Dailey-O'Cain, 2000; as cited in D'Onofrio, 2015, p. 243). IsConstantlyLying specifies that mean f0 is not a determining factor in sounding like a valley girl: "Even dudes with deep voices can talk like this." Lastly, Negative appraisal is made clear through adjectives such as annoying, moronic, and dumbass, and verbal constructions including annoys the shit out of me, drove me nuts, and you just want to throttle them. In another nested comment that responds to the top level comment, the user writes:

I think you highlighted a very prominent thing in gay dating when it comes to fem guys. Whenever some guy mentions fem, they usually add more to it with things like catty, valley girl types. I'm a feminine gay guy and I don't talk like a valley girl or a "diva". I have met a fem guy who was the stereotype you're talking about but that was one out 3 other fem guys I've met. I can say with some clarity that the average feminine gay guy doesn't act like that. [Kai_Decadence; T6, E2, r/askgaybros] 
Kai_Decadence contributes to the differentiation between speaking in a feminine way and talking like a valley girl being established in this online interaction. This user frames the adequation between feminine speech and valley girl speech as a commonlyencountered "stereotype" in the gay community while simultaneously denying its validity through examples from their own speech and experiences with people they have met.

In response to Kai_Dacadence's comment, a deleted user writes: "I think it goes to show there are different ways to be feminine and masculine. I like masculine guys too but that doesn't mean I like obnoxious jocks and dudebros.” Kai_Dacadence replies: "Exactly. Both sides have their extreme versions. 'HEY GIRL!' vs 'HEY BRO!' lol." References to "jocks" and "bros" serve as a masculine counterparts to the valley girl / stereotypical gay man that has been established earlier in the interaction. Thus, the users in this interaction imply that a stereotypically gay-sounding voice is not an issue because it is an indicator of femininity alone: this way of speaking is an issue because it is represents an "extreme" of gender-associated behavior.

The phrase valley girl is also present in top post 3 . On the subreddit $\mathrm{r} / \mathrm{ftm}$, a user asks in the title: How to not talk like I was socialized as a girl... In the description underneath the title, they explicitly note that they are not referring to pitch. The user shares that they are having dysphoria surrounding their communication and asks: "How $\mathrm{did} /$ do you guys pick up on male communication? I would like to come across as an adult male." They provide a list of speech features to focus on, including "avoid fillers such as 'like' and 'just"' and "don't end your sentences with a rising pitch if they're not questions" 
(two features that user IsConstantlyLying addressed in their comments on top post 2). A top level comment states:

I've heard cis guys who don't talk like this at all. Really, it's just the pitch you need. Sure, if you talk like a valley girl, you need to make some changes. But if you speak like everyone else, don't stress yourself out about it. [[deleted]; T6, E3, r/ftm]

Talking like a valley girl is contrasted with "speak[ing] like everyone else," highlighting its markedness. In a nested comment, user mountainfold discusses how lower pitch alone did not help them to sound as male as they would like, and that:

I have a lot of valley girl I've rooted out already but I know I have more to improve on. This is important to me to work on. [mountainfold; T6, TD3, r/ftm]

The comments from the deleted user and mountainfold make clear that a valley girl-esque voice is undesirable and that it is crucial to make one's own voice distinct from it. User djf87 replies to both in a nested comment that states:

I don't know, I know a few cis gay men who speak completely "like women" in pretty much every way- word choice, inflection, rhythm, all of it, but they have male pitch. They sound like men- effeminate, expressive men, but men. No one would ever think they weren't men... I think the average person just probably assumes they are gay, or thinks nothing of it. I haven't ever heard of them being misgendered on the phone- if it happens I bet it's rare. [djf87; T6, E3, r/ftm]

This comment argues speaking like a woman in male pitch still passes for male, but an "effeminate, expressive" version that is potentially legible as gay.

The cumulative effect of these comments is an intersubjective relation of adequation between the stereotypical gay voice and the valley girl persona, which users 
then orient away from. By invoking a stigmatized persona to align with a stereotypically gay voice, the users can more easily distance themselves from it. 


\section{Chapter 5: Discussion}

\subsection{Summary}

In this thesis, I explored discourses about "gay voice" and "sounding gay" in interactions between Reddit users through a two-tiered approach. In the first phase, I used topic modeling to get a zoomed-out view of what Reddit users are discussing when they talk about "gay voice." I found that the phrases "gay voice" and "sound* gay" are found in conversations where users are talking about the following themes: disliking their voice and asking how to change it; about the existence of a gay-sounding voice in languages other than English; about when a gay-sounding style began or how it came to be; the sound of one's recorded voice; and in discussions of pop culture. In the second phase, I focused on two of the topics derived from topic modeling whose keywords contained the root "feminin" (Topic 2 and Topic 6) to better understand how the "ideological link between femininity and male homosexuality" was being realized in specific interactions between users, and what these interactions could tell us about popular discourses about gender and sexuality in conversations about gay-sounding voices (Zimman, 2013, p. 8).

Within this second phase, I conducted a discourse analysis using both transitivity analysis and tactics of intersubjectivity analysis on excerpts from the 5 Reddit posts most strongly associated with Topic 2 and Topic 6 , respectively (10 total). Through the transitivity analysis, I discovered that users in the excerpts from both topics used a high rate of mental and material processes in their comments. However, the two topics 
differed in that excerpts from Topic 2 had a high rate of identifying intensive processes, while excerpts from Topic 6 had a high rate of attributive intensive verbs. Thus, users across both topics were positioning things as existing in relation to other things, but the Topic 2 users did so to define concepts, while Topic 6 users did so to assign attributes to the participants they discussed. I noted that this finding was related to the different types of subreddits that these discussions were found in. Topic 2 posts attempt to take an objective look at issues related to gay-sounding voices through a process in which an original poster asks a question, and users who comment are expected to provide a thorough answer, which in some cases needs to be supported by findings from academic articles. In this topic, "gay voice" is framed as a vocal phenomenon that exists out in the world that needs to be explained. The original posters in these excerpts address it from an outside perspective: it is something they have noticed but not necessarily a characterization of their own voices. The questions asked by original posters in excerpts in Topic 6 are related to their personal experiences and opinions. Topic 6 posts are of a more social nature (i.e. asking for advice or polling their Reddit peers). In this topic, "gay voice" is framed in a more personal manner. Posts in this topic address sounding gay as a way of characterizing their own voices or their potential dating partners'. Then, they distinguish between an extreme form to be avoided (in their own voices in the hopes of sounding more masculine, or in the voices of their partners because it is annoying/stigmatized), or if it is more moderate, then to be valued (in their own voices because it is more masculine than sounding female, or in the voices of their partners because it is attractive). 
Through the tactics of intersubjectivity analysis, I discovered that users across both topics utilize the tactic of adequation but do so to different ends. In Topic 2, I found that users adequate what gay men do with their voices to what straight men do with their voices, and paired this move with the tactic of denaturalization to point out that both groups (and all people) have variation in their speech that communicates their group membership(s). In Topic 6, I found that users adequate a stereotypically gay persona with the valley girl persona and then establish a relation of distinction between those two personae and either how they speak, how they prefer their partners to speak, or how they would like to sound.

Both of these findings were unexpected. With Topic 2, I did not anticipate that I would see people questioning the assumptions behind other user's inquiries. With Topic 6, I expected people to orient away from a gay-sounding voice, but I did not anticipate that they would make use of the valley girl persona to do this identity work, a character type that has been stigmatized in our culture for the past $30+$ years.

The transitivity analysis supports the findings from the tactics of intersubjectivity analysis. Users in the Topic 2 excerpts select a high rate of processes that define things, and they also adequate gay and straight ways of speaking to denaturalize the idea that what gay men are doing is unnatural. Defining what gay men are doing with their voices through identifying intensive verbs is how they are able to denaturalize the idea that it is unique. Users in the Topic 6 excerpts select a high rate of processes that define assign qualities to participants. They also adequate a stereotypically gay voice with a valley girl voice, and do so to create a distinction between their own voice and these ways of 
speaking. Using attributive intensive verbs to characterize voices as stereotypically gaysounding and valley girl-esque, and to classify their own voices as unlike these, is how these users are able to create a distinction between these personae's ways of speaking and their own. These two process types give Reddit users the tools to realize these tactics linguistically.

\subsection{Discussion}

The findings from the discourse analysis of Topic 2 excerpts raises the important issues of essentialism and markedness, or put another way, of whose speech gets questioned and why. In the context of this study, we see people going to the scientific forums of Reddit to find an explanation for a pattern they have noticed in gay male speech. People ask questions about "gay voice" or the "gay male accent" (terms which essentialize the actual intra- and intergroup variation that exists). They ask questions such as: where does it come from? How did it start? Is it biologically determined, or acquired through socialization, or is it an intentional identity performance? In other words, is it a choice? As Khan (2015) points out, there is no logical reason that these questions not be asked about the features found in straight men's voices, but they are not (or not often), and this has to do with which group is seen as "the norm from which all others diverge" (Bucholtz \& Hall, 2004a, p. 372). In the binary between gay and straight men, it is the latter, which we can trace back to who holds the most social capital in our current societal 
configuration. As a result, the speech that gets called into question and dissected is that of the minority group.

At the same time, we have evidence of people pushing back against these normative forces in this study. A key component of markedness is erasure: the unmarked norm is however the people with power in a society speak. This group establishes itself as the default and erases evidence that contradicts this vision. When users like millionsofcats and pyry adequate what gay and straight men are doing with their voices, they disrupt the assumption that straight ways of speaking are the standard, and thus weaken the erasure that maintains this idea. The fact that we see both forces at play (some Reddit users buying into the markedness while others are questioning it) speaks to a strength of this type of data: we get to see the contributions of a multitude of perspectives.

With regards to Topic 6 , the finding that users establish a relation of adequation between a stereotypical gay-sounding voice and the valley girl persona, which serves as an act of distinction between these two character types and either their own speech, how they want others to sound, or how they want their speech to be raises the issue that gaysounding voices are not [typically] perceived to be masculine, even though they come from male speakers. This confirms the point made by Zimman (2013) mentioned in the literature review:

Looking at variation among gay-sounding speakers reveals one of the linguistic manifestations of hegemonic masculinity, wherein a narrow range of acceptable masculinities is valorized while others are stigmatized through association with femininity or homoeroticism . . 
. do not lose sight of the diverse masculinities subjugated by hegemonic forces. (pp. 33-34)

Labeling someone's voice as gay becomes an easy way to dismiss their ability to lay claim to a valorized masculinity. Minding your verbal performance of masculinity is a big deal to people because there are material consequences — who gets picked for dating, for jobs, who gets bullied/harassed. As Munson (2011) writes:

Work on this topic should endeavor not only to contribute to variationist theory more generally, but to understanding the consequences of linguistic variation for the lives of people of diverse sexualities. Since my first publication on this topic (in Pierrehumbert et al. 2004), I have received a handful of e-mails from men who wish to change or eliminate their gay-sounding voices. While this is admittedly a nonrandom sample, it illustrates both the persistent homophobia that many sexual minorities face and the fact that phonetic variation is a trigger to this homophobia. (p. 27)

This is where the desire to orient away from it is coming from: people's awareness of or experiences with this being a quality that draws negative consequences. It is a product of this social conditioning that affects daily perceptions and reactions.

On the other hand, by aligning two stigmatized personas away from a more general femininity, these users are making a space for gender expression that does not rely on a bimodal framework of gender, i.e. one that does not place feminine and masculine at opposite ends of the same spectrum. Such a conception of gender is increasingly being circulated in our culture at this time, as demonstrated by the educational handout "The Gender Unicorn" shown in Figure 5.1. Trying to claim a masculinity that includes some feminine aspects, so long as it is not the stigmatized femininity that they position away from through their comments, is a step towards 
weakening the denigration of gay-sounding voices more generally. Through the combined adequation/distinction tactics seen in this data, these users could be pushing their own gay and feminine voices closer to the inner circle of acceptable masculinities while pushing other voices further away from it through not just an "association with femininity" but particularly an association with a feminine persona that has a cultural precedent of being disparaged (Zimman, 2013, p. 33).

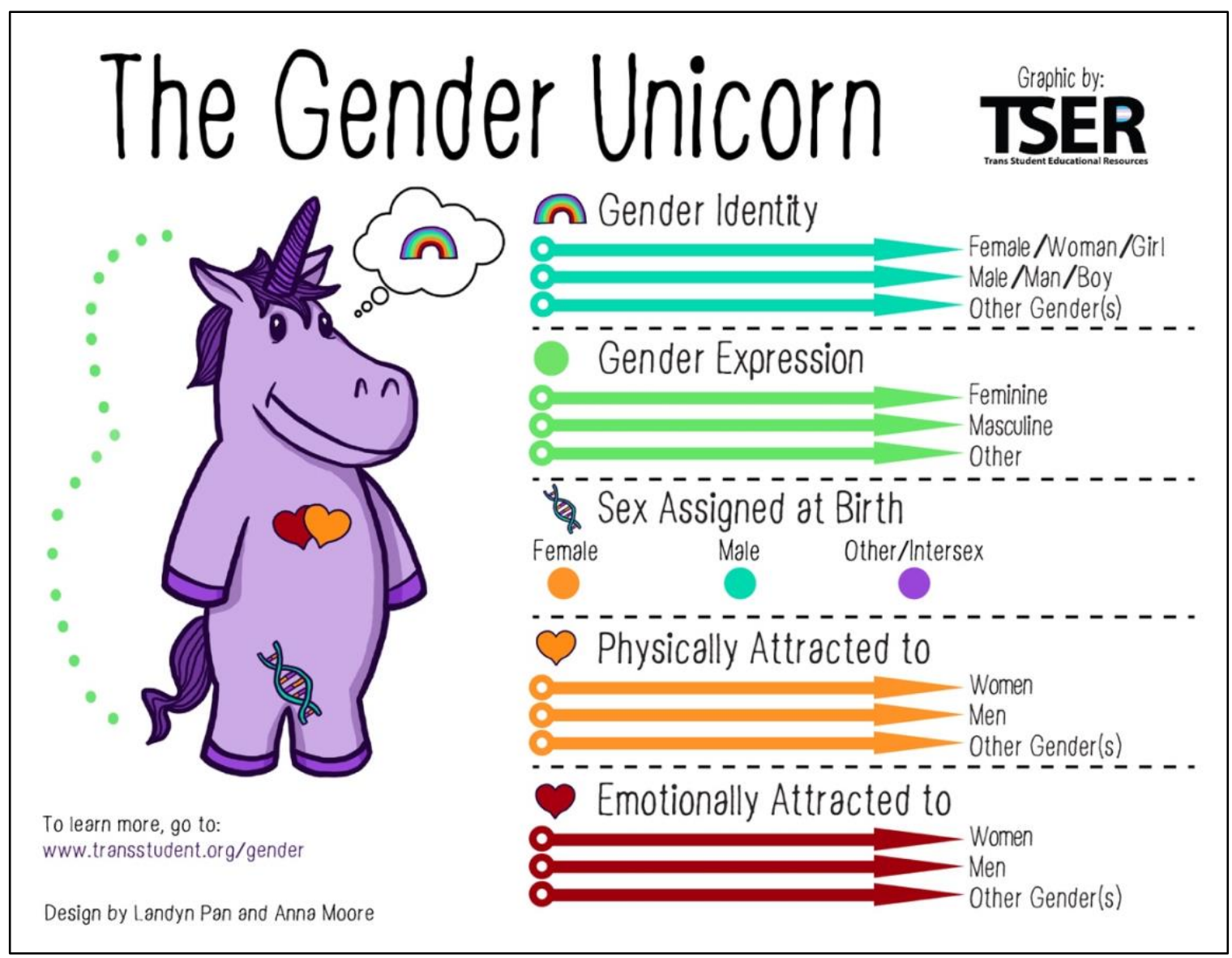

Figure 5.1. The Gender Unicorn: An infographic distributed by the group Trans Student Educational Resources (TSER). 


\subsection{Limitations and Future Directions}

One limitation of this study is that while I mention users making discourse moves in response to the power dynamics, I do not provide a full picture of what that actually means or give any background on how this situation came to be. Future researchers should address the issue of sounding gay through a critical discourse analysis, which would be able to address the historical, political, and economic factors that are relevant to understanding why the concept of gay-sounding voice exists, persists, and is important to understand.

Another limitation of this study is its lack of generalizability. The trends I find here cannot be extended to people who do not use the internet or Reddit in particular. I also draw on a convenience sample that in a strict sense only represents the users who happened to have posted or commented on the webpages that were selected for analysis. A broader interpretation, however, is that this research does represent a community of people who demonstrate an investment in this topic through their participation in these online conversations. This thesis has given me insight into the ideological perspectives of people for whom the discussion of gay-sounding voices is valuable enough for them to spend time reading, voting, and commenting on these posts.3 I recommend that future scholars analyze large corpora of crowdsourced online interactions to study gay-sounding voices and other issues related to language, gender, and sexuality. This type of analysis allows us to incorporate perspectives from a much larger number of participants than we are usually able to access and gives us insight into the ideological positioning of people 
who deem these issues to be relevant and devote their time to exploring them on these mediums.

\subsection{Conclusion}

This study has shown that Reddit users' perceptions about "gay voice" are no more monolithic than the way of speaking they discuss. These users reach out on this forum and bring up some of the major issues involved in discussing gay-sounding voices: essentialism, markedness, social capital, and discrimination. Gender and sexuality are indeed "intertwined," as Zimman (2013) noted, but users combine the established discourses in new ways to open the door for new discourses to come about. Törnberg \& Törnberg (2016), the paper that inspired the use of topic modeling in this research, note that studying social media texts can help us see how societal discourses are (re)produced in interactions between non-language professionals. I found that the discourses present are not simply being reproduced, they are being reconfigured. Doing so provides a way for users to reimagine the current social landscape and provide space for new conceptions about identity to emerge. 


\section{Endnotes}

1 The Python script described in this paper was originally used to collect the documents as well as perform topic modeling on them. I want to thank Dominique O'Donnell and Josh Farwell for writing this script and helping me to implement it.

2 I did not include the spreadsheet containing my transitivity coding in appendices of this document. However, please contact me at samulli77@gmail.com if you are interested in accessing this data.

3 I want to thank Steve Thorne for raising these points during my thesis defense. The language in this section is informed by his explanation.

$\mathrm{X}$ 


\section{References}

Anthony, L. (2019). AntConc (Version 3.5.8) [Computer software]. Tokyo, Japan:

Waseda University. Available from http://www.laurenceanthony.net/

Askgaybros. (n.d.). In Reddit [Webpage]. Retrieved October 20, 2019 from

https://www.reddit.com/r/askgaybros/

AskSocialScience. (n.d.). In Reddit [Webpage]. Retrieved October 20, 2019 from https://www.reddit.com/r/AskSocialScience/

Beresford, M. (2017, March 26). Research finds having a "gay voice" could stop you getting a top job. Pink News. Retrieved from http://www.pinknews.co.uk/2017/03/26/research-finds-having-a-gay-voice-couldstop-you-getting-a-top-job/

Besanvalle, J. (2017, March 26). Having a "gay voice" could cost you a top job, new study finds. Gay Star News. Retrieved from http://www.gaystarnews.com/article/gay-voice-cost-top-job-new-study-finds/

Blei, D., Ng, A., \& Jordan, M. (2003). Latent Dirichlet allocation. Journal of Machine Learning Research, 3(4/5), 993-1022.

Boyd-Graber, J. [Jordan Boyd-Graber]. (2013, October 21). Computational linguistics I: Topic modeling [Video file]. Retrieved from https://www.youtube.com/watch?v=4p9MSJy761Y

Brook, B. (2017, March 28). People with a "gay sounding" voices considered less able for top jobs. news.com.au. Retrieved from 
http://www.news.com.au/finance/work/careers/people-with-a-gay-soundingvoices-considered-less-able-for-top-jobs/newsstory/2765439f4de877a17bdb65c3fdb9a592

Bucholtz, M. \& Hall, K. (2004a). Language and identity. In A. Duranti (Ed.), A companion to linguistic anthropology (pp. 369-394). Hoboken, NJ: Blackwell Publishing Ltd.

Bucholtz, M. \& Hall, K. (2004b). Theorizing identity in language and sexuality research. Language in Society, 33(4), 469-515. doi:10.10170S004740450044021

Bucholtz, M. \& Hall, K. (2009). Locating identity in language. In C. Llamas \& D. Watt (Eds.), Language and identities (pp. 18-28). Edinburgh, UK: Edinburgh University Press. Retrieved from http://ebookcentral.proquest.com/lib/psu/detail.action?docID=536979

Cameron, D. (1997). Performing gender identity: Young men's talk and the construction of heterosexual masculinity. In S. Johnson \& U. H. Meinhof (Eds.), Language and masculinity (pp. 328-335). Oxford, UK: Blackwell.

Camp gay. (n.d.). In TV Tropes [Webpage]. Retrieved from https://tvtropes.org/pmwiki/pmwiki.php/Main/CampGay

Conrad, S. (2017). LING 476/576: Corpus linguistics, week 1, session 1 notes [Course presentation].

Cummins, K. (2017). 50 literary terms every English teacher should know. Literacy ideas for teachers and students. Retrieved from 
https://www.literacyideas.com/latest/2017/11/11/50-literary-terms-every-englishteacher-should-know

Davies, M. (2008-). The Corpus of Contemporary American English (COCA): 520 million words, 1990-present. Available from https://corpus.byu.edu/coca/

D'Onofrio, A. (2015). Persona-based information shapes linguistic perception: Valley Girls and California vowels. Journal of Sociolinguistics, 19(2), 241-256.

D'Onofrio, A. (2019). Complicating categories: Personae mediate racialized expectations of non-native speech. Journal of Sociolinguistics, 23(4), 346-366.

Du Bois, J. W. (2007). The stance triangle. In R. Englebretson (Ed.), Stancetaking in discourse: Subjectivity, evaluation, interaction (pp. 139-182). Philadelphia, PA: John Benjamins Publishing Company.

Eckert, P., \& Podesva, R. J. (2011). Sociophonetics and sexuality: Toward a symbiosis of sociolinguistics and laboratory phonology. American Speech, 86(1), 6-13.

Eggins, S. (2008). An introduction to systemic functional linguistics (2nd Ed.). New York, NY: Bloomsbury Academic.

Fasoli, F., Maass, A., \& Sulpizio, S. (2016). Communication of the "invisible": The case of sexual orientation. In H. Giles \& A. Maass (Eds.), Advances in intergroup communication (pp. 193-204). New York: Peter Lang Publications.

Fasoli, F., Maass, A., Paladino, M. P., \& Sulpizio, S. (2017). Gay-and lesbian-sounding auditory cues elicit stereotyping and discrimination. Archives of Sexual Behavior, 46(5), 1261-1277. 
Feinberg, A. (2017, July 28). A GOP staffer crowdsourced an anti-Clinton resolution from Reddit. Wired. Retrieved from https://www.wired.com/story/republicanstaffer-the-donald-resolution/

Fernandez, C. (2017, March 20). Gay men and lesbian women miss out on top jobs because of the sound of their voice, research claims. Daily Mail. Retrieved from http://www.dailymail.co.uk/sciencetech/article-4332378/Gay-people-don-tleadership-positions-work.html\#ixzz4c5Nu4jRj

Ftm. (n.d.). In Reddit [Webpage]. Retrieved October 20, 2019 from https://www.reddit.com/r/ftm/

Garfield, B. \& Vuolo, M. (Hosts). (2014, December 1). What does it mean to sound gay? [Audio podcast]. In B. Garfield \& M. Vuolo (Producers), Lexicon Valley. Retrieved from http://www.slate.com/articles/podcasts/lexicon_valley/2014/12/lexicon_valley_sp eech_scientist_benjamin_munson_on_the_stereotypical_gay.html

Gaudio, R.P. (1994). Sounding gay: Properties in the speech of gay and straight men. American Speech, 69(1), 30-57.

Gee, J. P. (2011). An introduction to discourse analysis: Theory and method. New York, NY: Routledge.

Gonella, C. (2017, March 25). Study: A gay-sounding voice could cost you a top job. $N B C$. Retrieved from http://www.nbcnews.com/feature/nbc-out/study-gaysounding-voice-could-cost-you-top-job-n738261 
Graham, S., Weingart, S., \& Milligan, I. (2018, September 6). Getting started with topic modeling and MALLET. The Programming Historian. Retrieved from https://programminghistorian.org/lessons/topic-modeling-and-mallet\#what-istopic-modeling-and-for-whom-is-this-useful

Gross, T. (Host). (2015, July 7). Filmmaker and speech pathologist weigh in on what it means to "sound gay" [Interview]. In T. Gross \& D. Miller (Producers), Fresh Air. Washington, DC: National Public Radio. Interview retrieved from http://www.npr.org/2015/07/07/420627143/filmmaker-and-speech-pathologistweigh-in-on-what-it-means-to-sound-gay. Transcript retrieved from http://www.npr.org/templates/transcript/transcript.php?storyId=420627143

Halliday, M. A. K. \& Matthiessen, C. M. I. M. (2004). An introduction to functional grammar (3rd Ed.). London, UK: Edward Arnold Publishers Ltd.

How Reddit works. (2014, July 30). In Upvoted. Retrieved from https://redditblog.com/2014/07/30/how-reddit-works-2/

Jones, J. (2017, March 27). Study suggests "gay voice" could cost you a job. Star Observer. Retrieved from http://www.starobserver.com.au/news/internationalnews-news/gay-voice-cost-jobs/156909

Kale, S. (2017, March 21). Men more likely to discriminate against people in jobs if they “sound gay" Vice. Retrieved from_https://broadly.vice.com/en_us/article/menmore-likely-to-discriminate-against-people-in-jobs-if-they-sound-gay

Karimzad, F., \& Sibgatullina, G. (2018). Replacing “them” with “us”: Language ideologies and practices of "purification" on Facebook. International Multilingual 
Research Journal, 12(2), 124-139.

doi:https://doi.org/10.1080/19313152.2017.1401449

Khan, S.D. (2015, July 8). Open letter to Terry Gross. Reed College. Retrieved from http://www.reed.edu/linguistics/khan/khan-lettertoterrygross.pdf

Kulick, D. (2000). Gay and lesbian language. Annual Review of Anthropology, 29(1), 243-285.

Levon, E. (2007). Sexuality in context: Variation and the sociolinguistic perception of identity. Language in Society, 36(4), 533-554.

Linguistics. (n.d.). In Reddit [Webpage]. Retrieved October 20, 2019 from https://www.reddit.com/r/linguistics/

Mack, S., \& Munson, B. (2012). The influence of /s/ quality on ratings of men's sexual orientation: Explicit and implicit measures of the "gay lisp" stereotype. Journal of Phonetics, 40(1), 198-212.

Mann, S. L. (2012). Speaker attitude as a predictive factor in listener perception of gay men's speech. Journal of Language and Sexuality, 1(2), 205-229.

Manning, C.D., Raghavan, P., \& Schütze, H. (2009). An introduction to information retrieval. Cambridge, UK: Cambridge University Press. Retrieved from https://nlp.stanford.edu/IR-book/pdf/irbookonlinereading.pdf

Mantle, L. (2015, July 9). New documentary examines the stereotype of 'sounding gay' [Audio podcast]. In KPCC, 89.3. AirTalk®: Southern California Public Radio. Retrieved from http://www.scpr.org/programs/airtalk/2015/07/09/43581/newdocumentary-examines-the-stereotype-of-soundin/ 
Meredith, N. (2017, March 20). Gay men and lesbian women less likely to be employed in a leadership position due to the sound of their voice. University of Surrey Media Centre. Retrieved from https://www.surrey.ac.uk/mediacentre/press/2017/gay-men-and-lesbian-womenless-likely-be-employed-leadership-position-due

Mimno, D. (2018). jsLDA: In-browser topic modeling [website]. Retrieved from https://mimno.infosci.cornell.edu/jsLDA/

Moore, N. (2015). Introduction to transitivity [Video file]. Retrieved from https://vimeo.com/119533054

Mulliner, S. (2017). Tactics of intersubjectivity analysis of YouTube comments on "Do I Sound Gay?" documentary trailer. Unpublished manuscript, Portland State University.

Munson, B., McDonald, E. C., DeBoe, N. L., \& White, A. R. (2006). The acoustic and perceptual bases of judgments of women and men's sexual orientation from read speech. Journal of Phonetics, 34(2), 202-240.

Munson, B. (2007). The acoustic correlates of perceived masculinity, perceived femininity, and perceived sexual orientation. Language and Speech, 50(1), 125142.

Munson, B. (2011). Lavender lessons learned; or, what sexuality can teach us about phonetic variation. American Speech, 86(1), 14-31. 
NoStupidQuestions. (n.d.). In Reddit [Webpage]. Retrieved October 20, 2019 from https://www.reddit.com/r/NoStupidQuestions/

Ochs, E. (1992). Indexing gender. In A. Duranti \& C. Goodwin (Eds.), Rethinking context: Language as an interactive phenomenon (pp. 335-358).

Onwuegbuzie, A. J., \& Denham, M. (2014). Qualitative data analysis techniques. Oxford Bibliographies Online in Education. doi:10.1093/obo/9780199756810-0078

Podesva, R. J. (2007). Phonation type as a stylistic variable: The use of falsetto in constructing a persona. Journal of Sociolinguistics, 11(4), 478 -504.

Porter, M. F. (1980). An algorithm for suffix stripping. Program, 14(3), 130-137.

Reddit content policy. (n.d.). In Reddit [Webpage]. Retrieved November 7, 2017, from https://www.reddit.com/help/contentpolicy/

Reddit. (n.d.). In Wikipedia [Webpage]. Retrieved November 7, 2017, from https://en.wikipedia.org/wiki/Reddit

Reddit.com traffic statistics. (n.d.). In Alexa [Webpage]. Retrieved November 7, 2017, from https://www.alexa.com/siteinfo/reddit.com

Regular expression reference: Word boundaries. (n.d.). In RegexBuddy [Webpage]. Retrieved November 12, 2017, from https://www.regularexpressions.info/refwordboundaries.html

Řehůřek, R. (n.d.). Corpora and vector spaces. gensim. Retrieved November 12, 2017, from https://radimrehurek.com/gensim/auto_examples/core/run_corpora_and_vector_s paces.html\#sphx-glr-auto-examples-core-run-corpora-and-vector-spaces-py 
Reynolds, D. (2017, March 23). Study suggests employers discriminate against candidates with "gay voice". Out. Retrieved from http://www.out.com/newsopinion/2017/3/23/study-suggests-employers-discriminate-against-candidatesgay-voice

Romano, A. (2017). Reddit just banned one of its most toxic forums. But it won't touch The_Donald. Vox. Retrieved from https://www.vox.com/culture/2017/11/13/16624688/reddit-bans-incels-thedonald-controversy

Sattelberg, W. (2019, July 22). The demographics of Reddit: Who uses the site? TechJunkie. Retrieved from https://www.techjunkie.com/demographics-reddit/

See the Film. (n.d.). In Do I Sound Gay? [Webpage]. Retrieved November 7, 2017 from http://www.doisoundgay.com/festival-screenings

Smith, C. (2019). 80 amazing Reddit statistics and facts. DMR. Retrieved from https://expandedramblings.com/index.php/reddit-stats/

Smyth, R., Jacobs, G., \& Rogers, H. (2003). Male voices and perceived sexual orientation: An experimental and theoretical approach. Language in Society, 32(3), 329-350.

Smyth, R. \& Rogers, H. (2008). Do gay-sounding men speak like women? Toronto Working Papers in Linguistics, 27, 129-144. Retrieved from https://twpl.library.utoronto.ca/index.php/twpl/article/view/6168

Stop words. (n.d.). In Wikipedia [Webpage]. Retrieved November 12, 2017, from https://en.wikipedia.org/wiki/Stop_words 
Sulpizio, S., Fasoli, F., Maass, A., Paladino, M. P., Vespignani, F., Eyssel, F., \& Bentler, D. (2015). The sound of voice: Voice-based categorization of speakers' sexual orientation within and across languages. PLOS ONE, 10 (7), 1-38.

Taylor, E. (2015, July 9). A documentarian wonders: “Do I sound gay?” National Public Radio. Retrieved from http://www.npr.org/2015/07/09/420909126/adocumentarian-wonders-do-i-sound-gay

Thorne, S. L. \& Ivković, D. (2015). Multilingual Eurovision meets plurilingual YouTube: Linguascaping discursive ontologies. In D. A. Koike \& C. S. Blyth, Dialogue in multilingual and multimodal communities (pp. 167-192). Amsterdam: John Benjamins Publishing Company.

Thorpe, D. (Producer, Director), \& Gertler, H. (Producer). (2014). Do I sound gay? [Motion picture]. United States: IFC Films (Sundance Selects), Impact Partners, Little Punk, \& ThinkThorpe. Retrieved from https://www.netflix.com/watch/80018333?trackId $=13752289 \& t c t x=0 \% 2 \mathrm{C} 0 \% 2 \mathrm{Ca}$ b6aba47bf0ac1f705719d19ff2bf5dcacce270f\%3A12f714ae4659ce64c1585b81ae0 c70c1a7ba87aa

Törnberg, A., \& Törnberg, P. (2016). Combining CDA and topic modeling: Analyzing discursive connections between Islamophobia and anti-feminism on an online forum. Discourse \& Society, 27(4), 401-422.

Valens, A. (2017, March 28). Straight men would rather promote men and women who don't "sound gay," study reveals. The Daily Dot. Retrieved from https://www.dailydot.com/irl/study-discriminate-gay-voice/ 
Vermeulen, R. (2016). Topic. Oxford Bibliographies Online in Linguistics. doi:10.1093/obo/9780199772810-0200

Zimman, L. (2013). Hegemonic masculinity and the variability of gay-sounding speech: The perceived sexuality of transgender men. Journal of Language and Sexuality, 2(1), 1-39. 


\section{Appendix A: Participants in Transitivity Analysis}

This appendix lists the participants that correspond to each process type that is delineated in §3.1.2.1. Labels used in coding are indicated with blue font. Participants that are optional for grammaticality are listed in parentheses.

Material (Pm)

\begin{tabular}{|l|l|l|l|}
\hline $\mathbf{A}$ & $\mathbf{G}$ & $\mathbf{R}$ & $\mathbf{B}$ \\
\hline actor & (goal) & (range) & (beneficiary) \\
\hline
\end{tabular}

\section{Mental (Pme)}

\begin{tabular}{|l|l|}
\hline $\mathbf{S}$ & $\mathbf{P h}$ \\
\hline senser & phenomenon \\
\hline
\end{tabular}

Verbal (Pv)

\begin{tabular}{|l|l|l|}
\hline Sy & $\mathbf{R v}$ & $\mathbf{V b}$ \\
\hline sayer & (receiver) & (verbiage) \\
\hline
\end{tabular}

\section{Behavioral $(\mathrm{Pb})$}

\begin{tabular}{|l|l|l|}
\hline $\mathbf{B e}$ & $\mathbf{B h}$ & $\mathbf{P h}$ \\
\hline behaver & (behavior) & (phenomenon) \\
\hline
\end{tabular}

\section{Existential (Px)}

$\mathrm{X}$

existent

\section{Relational - Identifying}

Intensive (Pi)

Circumstantial (Pcc)

\begin{tabular}{|l|l|}
\hline $\mathbf{T}$ & $\mathbf{V}$ \\
\hline token & value \\
\hline
\end{tabular}

Possessive $(\mathbf{P p})$
\begin{tabular}{|l|l|}
\hline $\mathbf{P r}$ & $\mathbf{P d}$ \\
\hline possessor & possessed \\
\hline
\end{tabular}

Causative (Pc)

\begin{tabular}{|l|l|l|}
\hline $\mathbf{T}$ & $\mathbf{V}$ & $\mathbf{A g}$ \\
\hline token & value & agent/assigner \\
\hline
\end{tabular}

\section{Relational - Attributive}

Intensive (Pi)

Circumstantial (Pcc)

\begin{tabular}{|l|l|}
\hline $\mathbf{C r}$ & $\mathbf{A t}$ \\
\hline carrier & attribute \\
\hline
\end{tabular}

Possessive (Pp)

\begin{tabular}{|l|l|}
\hline $\mathbf{P r}$ & $\mathbf{P d}$ \\
\hline possessor & possessed \\
\hline
\end{tabular}

Causative (Pc)

\begin{tabular}{|l|l|l|}
\hline $\mathbf{C r}$ & $\mathbf{A t}$ & $\mathbf{A g}$ \\
\hline carrier & attribute & agent/attributor \\
\hline
\end{tabular}




\section{Appendix B: Topics List with Top Posts}

This appendix provides a version of the topics list that shows which 5 top posts are most strongly associated with each (i.e. which posts best represent a given topic). Top post cells include the title of the post, the subreddit it was posted on, and a percentage that expresses how strong of an association exists between this post and the keywords in the same row.

Table A.1

Topics list with top 5 posts

\begin{tabular}{|c|c|c|c|c|c|c|}
\hline $\begin{array}{l}\text { Topic } \\
\text { ID \# }\end{array}$ & Keywords & Top Post \#1 & Top Post \#2 & Top Post \#3 & Top Post \#4 & Top Post \#5 \\
\hline 0 & $\begin{array}{l}\text { men } \\
\text { straight } \\
\text { sexual } \\
\text { women } \\
\text { social } \\
\text { sex } \\
\text { lesbian } \\
\text { woman } \\
\text { true } \\
\text { sens }\end{array}$ & $\begin{array}{l}\text { [Serious] Gay } \\
\text { people of reddit, } \\
\text { what stereotypes } \\
\text { about the gay } \\
\text { community are } \\
\text { actually pretty } \\
\text { accurate? } \\
\text { AskReddit } \\
21.4 \%\end{array}$ & $\begin{array}{l}\text { Why do many } \\
\text { gay men tend to } \\
\text { have that } \\
\text { distinct "gay" } \\
\text { voice? } \\
\\
\text { NoStupidQuestions } \\
16.2 \%\end{array}$ & $\begin{array}{l}\text { Why do a lot of } \\
\text { homosexuals } \\
\text { have that "gay } \\
\text { voice?" * } \\
\\
\text { NoStupidQuestions } \\
14.0 \%\end{array}$ & $\begin{array}{l}\text { Why do gay } \\
\text { men put } \\
\text { on/develop a } \\
\text { more feminine } \\
\text { voice? } \\
\text { AskReddit } \\
13.3 \%\end{array}$ & $\begin{array}{l}\text { How to stop } \\
\text { people from } \\
\text { thinking I'm } \\
\text { gay? } * \\
\text { AskMen } \\
12.7 \%\end{array}$ \\
\hline 1 & $\begin{array}{l}\text { com } \\
\text { http } \\
\text { vocaroo } \\
\text { fuck } \\
\text { youtub } \\
\text { video } \\
\text { thank } \\
\text { delet } \\
\text { fire } \\
\text { brand }\end{array}$ & $\begin{array}{l}\text { Off brand } \\
\text { cereals sound } \\
\text { like weird } \\
\text { euphemisms for } \\
\text { gay people } \\
\text { funny } \\
49.7 \%\end{array}$ & $\begin{array}{l}\text { Krogan with a } \\
\text { lisp is the most } \\
\text { badass character } \\
\text { in Andromeda * } \\
\text { TwoBestFriendsPlay } \\
35.6 \%\end{array}$ & $\begin{array}{l}\text { Storm Spirit Is } \\
\text { Definitely Gay } \\
\text { Right? } \\
\text { DotA2 } \\
29.9 \%\end{array}$ & $\begin{array}{l}\text { Why does } \\
\text { Richard } \\
\text { Jefferson sound } \\
\text { like an egg } \\
\text { when he talks? } \\
\text { nba } \\
22.8 \%\end{array}$ & $\begin{array}{l}\text { Bros, what does } \\
\text { your voice } \\
\text { sound like? } \\
\text { askgaybros } \\
18.6 \%\end{array}$ \\
\hline 2 & $\begin{array}{l}\text { speak } \\
\text { lisp } \\
\text { speech } \\
\text { men } \\
\text { cultur } \\
\text { homosexu } \\
\text { languag } \\
\text { feminin } \\
\text { differ } \\
\text { pattern }\end{array}$ & $\begin{array}{l}\text { Do people with } \\
\text { a "gay voice" } \\
\text { also speak that } \\
\text { way in foreign } \\
\text { languages } \\
\text { NoStupidQuestions } \\
35.5 \%\end{array}$ & $\begin{array}{l}\text { Honest question, } \\
\text { but what is the } \\
\text { story with the } \\
\text { 'gay' lisp? } \\
\text { AskSocialScience } \\
34.7 \%\end{array}$ & $\begin{array}{l}\text { Are } \\
\text { homosexuals in } \\
\text { non-english } \\
\text { speaking } \\
\text { countries } \\
\text { knowing for } \\
\text { having a "gay- } \\
\text { lisp"? * } \\
\text { NoStupidQuestions } \\
26.9 \%\end{array}$ & $\begin{array}{l}\text { I don't } \\
\text { understand why } \\
\text { male } \\
\text { homosexuals } \\
\text { have an "accent" } \\
\text { linguistics } \\
26.4 \%\end{array}$ & $\begin{array}{l}\text { How did the gay } \\
\text { accent } \\
\text { originate? } * \\
\text { linguistics } \\
24.1 \%\end{array}$ \\
\hline 3 & $\begin{array}{l}\text { talk } \\
\text { friend } \\
\text { straight }\end{array}$ & $\begin{array}{l}\text { Why do } \\
\text { Homosexual } \\
\text { men tend to }\end{array}$ & $\begin{array}{l}\text { Gay men of } \\
\text { Reddit: is the } \\
\text { voice a choice? }\end{array}$ & $\begin{array}{l}\text { Gay guys of } \\
\text { Reddit, is the } \\
\text { stereotypical }\end{array}$ & $\begin{array}{l}\text { Homosexual } \\
\text { men, is the "gay } \\
\text { voice" a forced }\end{array}$ & $\begin{array}{l}\text { Do gay men } \\
\text { across the world } \\
\text { speak their }\end{array}$ \\
\hline
\end{tabular}




\begin{tabular}{|c|c|c|c|c|c|c|}
\hline $\begin{array}{l}\text { Topic } \\
\text { ID \# }\end{array}$ & Keywords & Top Post \#1 & Top Post \#2 & Top Post \#3 & Top Post \#4 & Top Post \#5 \\
\hline & $\begin{array}{l}\text { stereotyp } \\
\text { normal } \\
\text { act } \\
\text { person } \\
\text { notic } \\
\text { girl } \\
\text { ask }\end{array}$ & $\begin{array}{l}\text { have a higher } \\
\text { pitched voice } \\
\text { compared to } \\
\text { Straight men? } \\
\text { AskReddit } \\
18.0 \%\end{array}$ & $\begin{array}{l}\text { Why or why } \\
\text { not? } \\
\text { AskReddit } \\
17.2 \%\end{array}$ & $\begin{array}{l}\text { gay guy voice a } \\
\text { choice or does it } \\
\text { happen without } \\
\text { your } \\
\text { knowledge? } \\
\text { AskReddit } \\
16.9 \%\end{array}$ & $\begin{array}{l}\text { thing or does it } \\
\text { just happen } \\
\text { naturally? } \\
\text { AskReddit } \\
15.9 \%\end{array}$ & $\begin{array}{l}\text { native languages } \\
\text { with the same } \\
\text { "gay inflection" } \\
\text { that's } \\
\text { stereotypical for } \\
\text { gay men here in } \\
\text { the states? } \\
\text { AskReddit } \\
15.6 \%\end{array}$ \\
\hline 4 & $\begin{array}{l}\text { accent } \\
\text { http } \\
\text { com } \\
\text { www } \\
\text { reddit } \\
\text { comment } \\
\text { org } \\
\text { southern } \\
\text { read } \\
\text { american }\end{array}$ & $\begin{array}{l}\text { Where did the } \\
\text { stereotype of } \\
\text { gay men } \\
\text { speaking with a } \\
\text { lisp originate? Is } \\
\text { it just an } \\
\text { English- } \\
\text { speaking } \\
\text { affectation, or is } \\
\text { it ascribed to a } \\
\text { larger queer } \\
\text { culture? } \\
\text { answers } \\
31.4 \%\end{array}$ & $\begin{array}{l}\text { Let's hear your } \\
\text { sexy voices, } \\
\text { bros. (kinda X- } \\
\text { post /r/askmen) } \\
\text { gaybros } \\
22.7 \%\end{array}$ & $\begin{array}{l}\text { Why do a lot of } \\
\text { homosexuals } \\
\text { have that "gay } \\
\text { voice?" * } \\
\text { NoStupidQuestions } \\
17.6 \%\end{array}$ & $\begin{array}{l}\text { Why do gay } \\
\text { people sound } \\
\text { gay? } \\
\text { NoStupidQuestions } \\
15.9 \%\end{array}$ & $\begin{array}{l}\text { Are } \\
\text { homosexuals in } \\
\text { non-english } \\
\text { speaking } \\
\text { countries } \\
\text { knowing for } \\
\text { having a "gay- } \\
\text { lisp"? * } \\
\text { NoStupidQuestions } \\
14.4 \%\end{array}$ \\
\hline 5 & $\begin{array}{l}\text { feel } \\
\text { fuck } \\
\text { life } \\
\text { love } \\
\text { live } \\
\text { hate } \\
\text { someth } \\
\text { never } \\
\text { right } \\
\text { find }\end{array}$ & $\begin{array}{l}\text { I don't want to } \\
\text { be gay :( } \\
\text { gaybros } \\
33.9 \%\end{array}$ & $\begin{array}{l}\text { His voice is a } \\
\text { complete turn } \\
\text { off and now I } \\
\text { don't know what } \\
\text { to say* } \\
\text { gay } \\
27.9 \%\end{array}$ & $\begin{array}{l}\text { Insecure with } \\
\text { my gay voice, } \\
\text { how to feel less } \\
\text { like shit? } \\
\text { gay } \\
18.2 \%\end{array}$ & $\begin{array}{l}\text { How to stop } \\
\text { people from } \\
\text { thinking I'm } \\
\text { gay?* } \\
\text { AskMen } \\
16.8 \%\end{array}$ & $\begin{array}{l}\text { The dreaded } \\
\text { "gay voice" } \\
\text { askgaybros } \\
16.8 \%\end{array}$ \\
\hline 6 & $\begin{array}{l}\text { tri } \\
\text { chang } \\
\text { someon } \\
\text { speak } \\
\text { tell } \\
\text { high } \\
\text { pitch } \\
\text { feminin } \\
\text { probabl } \\
\text { good }\end{array}$ & $\begin{array}{l}\text { Voice on } \mathrm{t} \\
\mathrm{ftm} \\
34.2 \%\end{array}$ & $\begin{array}{l}\text { I won't hook up } \\
\text { with guys with a } \\
\text { "gay voice". } \\
\text { Does this mean } \\
\text { I'm a bad } \\
\text { person? } \\
\text { askgaybros } \\
27.0 \%\end{array}$ & $\begin{array}{l}\text { How to not talk } \\
\text { like I was } \\
\text { socialized as a } \\
\text { girl... } \\
\text { ftm } \\
26.2 \%\end{array}$ & $\begin{array}{l}\text { Is "gay-voice" a } \\
\text { turn on to } \\
\text { anyone? } \\
\text { askgaybros } \\
25.2 \%\end{array}$ & $\begin{array}{l}\text { Is the } \\
\text { stereotypical } \\
\text { gay voice an } \\
\text { instant turn-off } \\
\text { for you? } \\
\text { askgaybros } \\
25.0 \%\end{array}$ \\
\hline 7 & $\begin{array}{l}\text { still } \\
\text { actual } \\
\text { pretti }\end{array}$ & $\begin{array}{l}\text { Krogan with a } \\
\text { lisp is the most } \\
\text { badass character }\end{array}$ & $\begin{array}{l}\text { His voice is a } \\
\text { complete turn } \\
\text { off and now I } \\
\text { don't know what }\end{array}$ & $\begin{array}{l}\text { KickStarter for } \\
\text { documentary on } \\
\text { the "gay voice" - } \\
\text { - thought some }\end{array}$ & $\begin{array}{l}\text { Do I Sound } \\
\text { Gay? - a new } \\
\text { documentary on } \\
\text { the 'gay voice', }\end{array}$ & $\begin{array}{l}\text { How do I lose } \\
\text { the 'gay voice' ? }\end{array}$ \\
\hline
\end{tabular}




\begin{tabular}{|c|c|c|c|c|c|c|}
\hline \multirow{2}{*}{$\begin{array}{l}\text { Topic } \\
\text { ID \# }\end{array}$} & Keywords & Top Post \#1 & Top Post \#2 & Top Post \#3 & Top Post \#4 & Top Post \#5 \\
\hline & $\begin{array}{l}\text { point } \\
\text { alway } \\
\text { reason } \\
\text { call } \\
\text { put } \\
\text { person } \\
\text { work }\end{array}$ & $\begin{array}{l}\text { in Andromeda * } \\
\text { TwoBestFriendsPlay } \\
22.3 \%\end{array}$ & $\begin{array}{l}\text { to say } * \\
\text { gay } \\
19.8 \%\end{array}$ & $\begin{array}{l}\text { of you might be } \\
\text { interested to } \\
\text { know about it } \\
\text { linguistics } \\
17.3 \%\end{array}$ & $\begin{array}{l}\text { where it comes } \\
\text { from, and if it } \\
\text { can be "fixed" } \\
\text { gaybros } \\
17.2 \%\end{array}$ & $\begin{array}{l}\text { askgaybros } \\
16.2 \%\end{array}$ \\
\hline 8 & $\begin{array}{l}\text { question } \\
\text { post } \\
\text { remov } \\
\text { ask } \\
\text { anyth } \\
\text { simpli } \\
\text { edit } \\
\text { act } \\
\text { delet genet }\end{array}$ & $\begin{array}{l}\text { What is the } \\
\text { origin of the } \\
\text { "gay accent"? } \\
\text { AskHistorians } \\
37.2 \%\end{array}$ & $\begin{array}{l}\text { His dad just } \\
\text { realized his son } \\
\text { is gay. } \\
\text { funny } \\
20.2 \%\end{array}$ & $\begin{array}{l}\text { How did the gay } \\
\text { accent } \\
\text { originate? } * \\
\text { linguistics } \\
15.9 \%\end{array}$ & $\begin{array}{l}\text { Questions on } \\
\text { nasality, } \\
\text { "nasality", and } \\
\text { gay-sounding } \\
\text { voices * } \\
\text { linguistics } \\
15.2 \%\end{array}$ & $\begin{array}{l}\text { ELI5: Why do } \\
\text { some gay men } \\
\text { "sound" gay, I.E } \\
\text { have some sort } \\
\text { of gay accent } \\
\text { (serious) } \\
\text { explainlikeimfive } \\
11.2 \%\end{array}$ \\
\hline 9 & $\begin{array}{l}\text { record } \\
\text { hear } \\
\text { frequenc } \\
\text { head } \\
\text { differ } \\
\text { ear } \\
\text { http } \\
\text { pitch } \\
\text { sing } \\
\text { deeper }\end{array}$ & $\begin{array}{l}\text { Is the recording } \\
\text { of my voice } \\
\text { really what my } \\
\text { voice sounds } \\
\text { like? Why does } \\
\text { it sound more } \\
\text { "nasally" than } \\
\text { when I hear my } \\
\text { voice directly? } \\
\text { askscience } \\
44.7 \%\end{array}$ & $\begin{array}{l}\text { TIL the reason } \\
\text { why we hate the } \\
\text { recorded sound } \\
\text { of our voice is } \\
\text { because our } \\
\text { skull changes } \\
\text { the resonance of } \\
\text { our voice from } \\
\text { within and } \\
\text { creates more } \\
\text { bass. When we } \\
\text { hear a digital } \\
\text { recording of our } \\
\text { voice, although } \\
\text { slightly } \\
\text { unfamiliar to } \\
\text { ourselves, it's } \\
\text { exactly how } \\
\text { other people } \\
\text { hear it. }\end{array}$ & $\begin{array}{l}\text { Why do we } \\
\text { often hate the } \\
\text { sound of our } \\
\text { own voice on } \\
\text { recorded } \\
\text { devices? } \\
\text { answers } \\
28.5 \%\end{array}$ & $\begin{array}{l}\text { Questions on } \\
\text { nasality, } \\
\text { "nasality", and } \\
\text { gay-sounding } \\
\text { voices * } \\
\text { linguistics } \\
18.6 \%\end{array}$ & $\begin{array}{l}\text { ELI5: Why do } \\
\text { people sound } \\
\text { like their } \\
\text { respective } \\
\text { gender even if } \\
\text { they have a } \\
\text { high/low voice? } \\
\text { explainlikeimfive } \\
15.3 \%\end{array}$ \\
\hline
\end{tabular}




\section{Appendix C: Excerpts from Topic 2 and Topic 6 Posts}

In this appendix, I provide full copies of the excerpts I analyzed from each of the top 5 posts associated with Topic 2 and Topic 6, respectively. Listed first is information about the post overall (subreddit, user who created it, title, and description). The excerpts I selected begin after the bold font.

\section{[Topic 2, Excerpt \#1]}

Retrieved on 10/12/2018 from

https://www.reddit.com/r/NoStupidQuestions/comments/6aa7o0/do_people_with_a_gay_voice_also_speak that_way_in/

Posted in r/NoStupidQuestions by u/weab00: Do people with a "gay voice" also speak that way in foreign languages

I've been kind of wondering this lately, ever since I saw a documentary on gay speech. I would presume so, given that their pronunciation of words would simply be applied to another language. But perhaps there isn't that cultural/psychological tie in a connection to a foreign language like there would be with their native one.

- yearofthebird The Japanese "okama" has an effeminate and unique way of speaking.

- Crimsai What's an okama?

- 10derps Here you go \{LINK: 6-second clip from the TV show South Park features a video gaming system named Okama Game Sphere

- ButtsexEurope Basically means faggot. It implies a guy who dresses up as a girl or is very feminine in general. It can also mean a trap. For example, if you pretend you're a girl online, you're called a nekama (net okama). There was a "controversy" over a game called Akiba's Trip where you play as a guy who fights vampires. There's an epistolary mechanic where you find out who the vampires are and where they'll be by reading what's basically $2 \mathrm{chan}$. Part of the dialogue you read is translated as "Shut up, you trap!" The Japanese dialogue says, iirc "urusei, nekama!" It literally means "Shut up, you trap!" Some SJWs got offended at this because it's "transphobic." I mean, the only other way to translate it faithfully would be "Shut up, faggot!" The literal translation "Shut up, you female impersonator looking for attention on the internet" doesn't flow very well.

- xain1112 From context I'm assuming it's a stereotypical gay man. 
- yearofthebird It's a stereotypical gay dude, just like the other guy said.

- IparryU Ya, they can also bust out their real voice too... saw some okama get in a guys face with an attitude change. Dude backed down, then went back to okama. Quite sure that okama would have thrown a beat down too.

\section{[Topic 2, Excerpt \#2]}

Retrieved on 10/12/2018 from https://www.reddit.com/r/AskSocialScience/comments/1759i6/honest_question_but_what_is_the_story_wi th thel

Posted in r/AskSocialScience by $u /[$ deleted]: Honest question, but what is the story with the 'gay' lisp?

\section{[deleted]}

- JoanCrawford Gay dude here. I have no empirical evidence for this, but my theory is that it comes from taking behavioral cues from women instead of men while growing up. As Aksalon mentions, it's not a lisp. It's a different $\mathrm{S}$ sound, and it's much more common to hear women make this sound than it is to hear (straight) men do it. Go youtube any video of Maggie Gyllenhaal and you'll see what I mean - you may never have noticed her doing it before, but you would have noticed if a man had been making that sound. It's pretty normal for a woman to do it; it's unusual for a man to do so.

I think some gay boys, way before they know they're gay, unconsciously pay more attention to and imitate the way women behave, more than they pay attention to and imitate the way straight men behave. Hence, the $\mathrm{S}$ sound and more effeminate gestures in general.

- taking_all_bets I love your username.

- JoanCrawford Haha, thank you.

Or rather - NO... WIRE HANGERS...... EVER!!!!

- PhineasPhage Not all gay men are effeminate though, or at least they don't have a feminine gender expression - so is "the lisp" only true for that group?

- missinfidel I think you would find it to be a more common speech pattern in effeminate gay men. Not all gay men exhibit the gay lisp.

- JoanCrawford Well, no. I think this is a major contributor, but not the only one. As others in this thread have pointed out, some people "take on" the behavior around other gay guys, consciously or unconsciously. I could see this being related to feeling a sense of community and/or as an indicator that one is gay just like the others in the group. But the take-away is that while I suspect it stems from larger gendered behaviors in American culture (I really can't speak outside of my experience with other gay American men), it still shifts and changes depending on the person and the context. 
As a side note, your question implies that there's a group of men who are effeminate and one that isn't, and that the "lisp" is separate from that effeminacy. I'm probably preaching to the choir, but just in case - there's no clear-cut difference between "effeminate" guys and "non-effeminate" guys (it's a spectrum, and one that, in my mind, is composed of several behaviors and characteristics including the "lisp," vocal inflection, wrist limpness, posture, excitability, interest in stereotypical "feminine" things/activities). Some gay guys who "lisp" are hunters and fighters, some gay guys who seem "straight" or "butch" love interior design and baking.

EDIT: Oh, also, not all women do this. So I think it probably depends on the women who are around while growing up for the boy to model.

- $\quad$ hachijuhachi I'm reading this whole thing with very hissy s's.

- $\quad$ PhineasPhage Oops, didn't mean to imply that effeminate and masculine gay men were mutually exclusive - I was trying to acknowledge the spectrum and ask (disingenuously) if those behaviors were only true for men with gender expressions more on the feminine side of things.

- JoanCrawford I had a feeling, but wanted to err on the side of giving more information just in case :)

- Peaceandallthatjazz As one person said, I think it is more common among those who identify as effeminate.

Anecdotal evidence: I do have a butch gay guy friend who has a very light lisp that is more pronounced when he gets excited :)

\section{[Topic 2, Excerpt \#3]}

Retrieved on 10/12/2018 from

https://www.reddit.com/r/NoStupidQuestions/comments/2zl9ry/are_homosexuals_in_nonenglish_speaking countries/

\section{Posted in r/NoStupidQuestions by u/kruminator 13: Are homosexuals in non-english speaking countries knowing for having a "gay-lisp"?}

- Quetzie Judge for yourself! \{LINK: YouTube video that is no longer available. From context, it seems to have been a recording of (a) gay-identified Dutch speaker(s)\}

Anyway, the lisp isn't the defining feature, the 'singy' way of speaking more, you know, feminine.

A real lisp was never that common until recently.

- NikolaTeslal I gotta ask, why talk with the lisp? 
- MrDingleberrry It's fabulous.

- $\quad$ lurkinreddit "Ith fabulouth"

oyohval What language is this?

- Devisioned Dutch.

- oyohval Thanks

- hotbowlofsoup The singy way of speaking is more because their accent is from Amsterdam. They speak like old ladies from Amsterdam though.

I think that's more it. It's not an accent, it's just a more effeminate way of speaking.

- blauman Aw man I wonder what they're saying, looks funny. Also TIL dutch sounds kinda slurpy at times.

- [deleted] There definitely is a Dutch gay accent.

○ Prutzle But not with a lisp... Interesting :)

- BelchSpawn Can you describe it? Or are there the same differences from standard speech as there are in english?

- Flater420 It just sounds slightly more effeminate. In some cases, the fact it sounds forced is a giveaway as well.

- [deleted] I don't know either of the accents well enough to compare, sorry. I recognize them when I hear them, that's all.

\section{[Topic 2, Excerpt \#4]}

Retrieved on 10/12/2018 from

https://www.reddit.com/r/linguistics/comments/d1i0c/i_dont_understand_why_male_homosexuals_have_a n/

Posted in r/linguistics by u/tripplethrendo: I don't understand why male homosexuals have an

"accent".

I am not homophobic. The way that male gays talk doesn't even really bother me unless it's overtly flamboyant, I find myself sensitive to loud talking no matter who it is. I don't understand why part of

this social group adopts such a specific speaking pattern. I know a few gay men who don't talk this way at all. 
- Facepuncher OK but what i dont understand is where the gay accent comes from to begin with. It just sounds like a guy trying to imitate a typical estrogen charged female. Did one gay guy somewhere just decide he wanted to start talking like a girl as a means to show hes gay and it just blew up around the world over time?

Is estrogen a true correlation to that kind of speech in women? Because all women don't talk like that. But then if it were linked to estrogen, then this would mean all flamboyantly gay mean would be growing breasts, and I dont see that happening.

This is why I feel its just a learned thing that gays choose to do to be less manly, but what i do not understand is that being gay has nothing to do about being less of your current gender and being more like the other one but instead its just about LIKING your same gender. Why would you as a gay man want to act more feminine when other gay men don't like females? It's like defeating the purpose of attracting a mate of the same sex just because they feel the need to stand out.

- pyry You're probably aware, but you have two separate sets of questions here: those about language, and those about just the non-linguistic nature of gay people in general. I'll get to both.

Language use

"Is estrogen a true correlation to that kind of speech in women? Because all women don't talk like that. But then if it were linked to estrogen, then this would mean all flamboyantly gay mean would be growing breasts, and I dont see that happening."

Maybe for pitch of voice in women, but it has nothing to do with anything in men. As far as I'm aware (but I haven't followed the research), gayness isn't about estrogen. Yes, there are similarities between gay speech and the way some girls speak, but this doesn't necessarily mean the goal is to sound like a woman, nor is it true that all gay men speak this way. Similarly, there are cultures where men overall (straight ones included) typically speak in higher voices, and act in ways that people from an American background would consider more feminine, and this has nothing to do with estrogen; it's mostly just language. Again, people use language as a tool to communicate thoughts, but also as a tool to communicate what kind of person they are.

Mostly what people notice about gay speech, and specifically a stereotypical gay accent are things that make people sound feminine overall, such as the way people pronounce /s/, or certain word choices. There are several other parts to gay speech that, without these more obvious features, could probably make someone slip under most peoples' radar, despite the fact that they're clearly gay to those that it's important to know.

I guess I can't say what the motivation was, or whether it was someone in specific who started this, but there are several possibilities: societal opposition to gayness meant that gay guys needed a way to identify themselves to fellow gays without being obvious about it to outsiders who would punish them in some way for it. Another possibility is that when you're young and realize that you're interested in people of the same sex, perhaps one aspect of dealing with this as a child is to see "oh, girls date guys, maybe I should act more like a girl too"... But, this really doesn't apply to all 
men at all. Speaking for myself, I wasn't girly when I was little, but I remember liking guys as well as girls.

Sexuality

"This is why I feel its just a learned thing that gays choose to do to be less manly..."

Yeah, just like it's a learned thing for straight people to act the way they do. There are cultures in the world where gender identity is not just about being male and female, and this is something that is accepted throughout the whole culture by everyone.

“... what $i$ do not understand is that gay has nothing to do about being less of your current gender and being more like the other one but instead its just about LIKING your same gender. Why would you as a gay man want to act more feminine when other gay men don't like females?"

For some people, yes. It's important to distinguish between homosexuality in general in terms of having sex with people of the same gender, versus adopting the cultural aspects. Not everyone does this. Not all guys who like guys like guys who are culturally really gay. Some do, and I think the people who display their sexuality in obvious ways may be at an advantage but only if they're looking for people who like these things about them. If you don't really broadcast it, unless you're open about being interested in guys, it may be a bit more difficult for people to be aware of this.

Why, though? I feel like in the U.S., we're just getting over a large cultural trend of sexual conservativeness. Part of this appears to be some sort of backlash, where people (regardless of gender and sexual identity) may be more into identifying in some nonsexual way with what their sexual interests or orientation is/are. I currently live in a country where people are more comfortable talking about sex, and gayness is no big deal, and I feel like although there are some people who are really obviously gay, quite a lot of people here are much more flexible and they don't bother to broadcast it in the way they speak, or the way they behave (you know, outside of who they have sex with).

In the U.S., I think it's not just gay people who are wont to express sexuality through culture, but many many other groups, and even straight people.

So, why would gay men want to act more feminine when other gay men don't like females? There's quite a range to gender behavior, and people are many kinds of things. There are also people who like all sorts of different people, so while not all gay men act really feminine, there are gay men who both like (or are attracted to) this behavior, and those who do not. It may just be easier to identify people who really stand out for those who haven't spent a lot of time thinking about or dealing with it. It's not defeating the purpose in any means... Also, I know plenty of straight guys who are attracted to more masculine women, and likewise straight women who are attracted to more feminine guys (but in this case, feminine in the sense of say, Legolas). I guess you might say they should just be gay instead.

$\mathbf{t l} ; \mathbf{d r}$ : there is a lot of variety to gender identity and sexual identity and how and whether people reflect it culturally, either through language or behavior. Just because someone's gay doesn't mean that they have to behave in a certain way, and the same is 
true for straight people (but people just notice it a lot less), comic book geeks, physicists, and many other things where people spend enough time together due to geographical location, or special interest. I realize this probably just answered your questions with a lot more questions, but I hope it helped. It's a bit hard to explain when I see where your questions are coming from. These are by no means perfect answers, but just an attempt to help you along the way to getting it. Ask more questions if you need.

\section{[Topic 2, Excerpt \#5]}

Retrieved on 10/12/2018 from

https://www.reddit.com/r/linguistics/comments/6rp0ts/how_did_the_gay_accent_originate/

Posted on r/linguistics by u/Bobbers8: How did the gay accent originate?

Where did the gay accent originate from and how long has it been around? I'm not even really talking about a feminine manner of speaking, but rather the very popular drawn out "lisp and sass" that seems to be prevalent across several western languages.

- DonaNobisPacman I'm scared to comment, given the comment graveyard below!

By "lisp" I assume you're talking about the frontal articulation of /s/ \{LINK: to Wikipedia page on "gay male speech"\}, supported by studies like this \{LINK: to Mack \& Munson (2012)\}. There's not really consensus on "where it came from" but a common folk perception is that it imitates stereotypical "feminine" speech. One theory is that the use of fronted /s/, like other linguistic variables (e.g. slang), serves as an identity marker for gay men to show that they are part of a larger speech community.

EDIT:

"Do I Sound Gay?" \{LINK: YouTube copy of the documentary that has been taken down for copyright reasons $\}$ is a documentary on the subject. It's apparently questionable!

This \{LINK: 6-minute excerpt from the documentary posted on NYT \} is the short documentary that I was thinking of, and it interviews a few men about what makes people sound gay. Plus it shows some cool sonographs and mentions the fronted $/ \mathrm{s} /$ !

- Millionsofcats There is another (or perhaps, complementary) interpretation: A retracted /s/ serves as a marker of identity--a masculine one. This is discussed in studies such as this one $\{$ LINK: to Podesva \& Hofwegen (2014)\}, which propose a correlation between social conservatism and $/ \mathrm{s} /$ retraction in straight men.

That is, it's an error to assume it's only gay men who express their identity through their speech; we could also talk about a "straight male accent" and its origins--of course, with the same caveats as for the "gay male accent," which isn't used by all gay men. It's just that no one really has neutral, unmarked-for-identity speech.

- Bobbers8 Forgive my layman approach to this, but doesn't every language follow a certain lineage? 
In this lineage, how long has the straight male retracted /s/? How long have gay men expressed their identity through speech?

In other words, did one diverge from the other? Or have both manners flowed down as long as linguistic history can remember?

Again, I'm a layman (also not a gayman), be gentle \{laughing emoji\}

- millionsofcats I'm not quite sure what you're asking about lineage, but if I'm guessing correctly: Yes, every language is descended from an earlier language*. This thread is mostly talking about English, so yes, every variety of English that people speak today is descended from an earlier English.

"In this lineage, how long has the straight male retracted /s/?"

We don't know the answer to this, because we haven't been doing detailed phonetic studies for very long - we didn't have the equipment, and we had to spend a long time on the basic foundations of phonetics before we got into more specific questions.

"How long have gay men expressed their identity through speech?"

Broadly speaking, as long as everyone else has been expressing their identity through speech: Since the dawn of modern human language. But if you're asking how long ago gay men were expressing a specifically gay identity through speech, that's a really complicated question. The way that we conceptualize sexuality varies a lot by time and place. In addition, we would be relying on historical records, which can be spotty and inaccurate.

I'm not an expert on this history so I can't really comment. But there may be a linguist or historian somewhere who knows more. This might actually be a good question for /r/askhistorians \{LINK: to the subreddit askhistorians \} - they might know more about the historical records than people here.

"In other words, did one diverge from the other?"

This question is also hard to answer because of how new the research is. One thing that's been proposed is that when men retract their pronunciation of $/ \mathrm{s} /$, it emphasizes acoustic differences between their speech and female/feminine speech. In that way, it would be like men lowering the pitch of their voices: There are average acoustic differences already, because of differences in the size of male and female vocal tracts, but in some cultures men speak in an even lower pitch, exaggerating the difference. This varies by culture, so there's no reason to assume that it has always been this way in any particular one. 
One possibility is that neither straight men nor gay men are using the "original" pronunciation of $/ \mathrm{s} /$. Perhaps straight men are moving in one direction, and gay men in the other. I don't know, though.

* With the possible exceptions of languages like creoles and conlangs, depending on what you mean by "descend."

- DonaNobisPacman Good points! Linguists tend to privilege straight male speech as the norm against which to measure "deviant" speech such as female or gay speech, when really we should consider that straight male speech may itself be subject to variation.

[Topic 6, Excerpt \#1]

Retrieved on 10/12/2018 from https://www.reddit.com/r/ftm/comments/3n69c0/voice_on_t/

Posted on $r / f t m$ by $u /[$ deleted]: Voice on $t$

does anyone know how to not have "gay voice" when your voice drops? Please do not be offended, but I know a lot of guys on $t$ who sound like stereotypical gay men once they start $t$. I think its the intonation. Im a straight guy and i dont want other dudes calling me gay because of my voice. Is there anything $i$ can do to change how i speak? I have a "feminine" voice and my intonation is also feminine.

- yggdrasils_roots Something a lot of trans men don't realize is that men don't have the same ways of communicating things as women a lot of the time. Some quick examples:

- Women repeat things. It isn't cold, or really cold, it is really really really cold.

- Women tend to raise the pitch of their voice up and down during sentences while men tend to stay closer to the same. "I am PISSED!" for a woman sounds way different than when a man says "I am pissed."

- Women end their sentences with a high note more often. AKA Uptalk or High Rising Terminal. To varying degrees of course.

- Women speak more softly than men.

- Men tend to speak more aggressively than women, use more words that imply action.

- Men use a surprising amount of sound effects to describe things.

- Women tend to interrupt people way more often when speaking, even if that's just to speak over the other person to agree.

That's just the very basics of patternage. Then there's the issue of actual voice things. Like, do you use your chest voice or head voice? If your throat feels tight when you're talking, or you speak at the same place in the throat you did before transitioning, you're using a head voice. After taking testosterone, the vocal chords change and thicken. People don't, but they should learn to speak with a relaxed open throat to allow the body to speak from the chest and get the full range of depth. That higher, almost artificial sound/"buzzy" voice most FTMs have I heavily suspect is because of this - reason being, I have it myself if I don't actually open my throat. 
You don't have to have "gay voice". I'm pretty gay myself and don't have the "flamer" tone. I actually hate that with a passion, myself. If you work at changing the way you say things and learn to change where you speak, you'll be fine.

- secretagentpoyo At the LA LGBT Center, they were only going to offer Vocal Feminization workshops for transfeminine women because lo, there aren't any transmasculine people organizing any part of the TransLounge. I said something that got passed along to the organizers and for every reason you listed, there's gonna be a Vocal Masculinization workshop too.

- yggdrasils_roots That's awesome! I'm glad that there's going to be something for both sides of the issue. Trans men are often left aside when it comes to voice stuff because people assume that $\mathrm{T}$ does all the work when it doesn't. I hope it helps people!

- [deleted] " but they should learn to speak with a relaxed open throat to allow the body to speak from the chest and get the full range of depth. "....how do you even do that?

- yggdrasils_roots Relax the muscles in your throat. Let your tongue go slack (it will be more towards the back of your throat), lips closed but jaw relaxed. Sit that way for a moment or two. Try and think about how it feels and be aware of it. Now say a few words and pay attention to how your throat feels. It should not feel tight. You should not be closing off your throat much at all to speak. This is what women generally do, as it produces a softer and more feminine sound. Try and keep your throat from tensing when you talk. Sit up straight and speak with fuller breaths. You will speak in a louder and lower register if you do that.

\section{[Topic 6, Excerpt \#2]}

Retrieved on 10/12/2018 from

https://www.reddit.com/r/askgaybros/comments/5c71iu/i_wont_hook_up_with_guys_with_a_gay_voice_d oes/

Posted on r/askgaybros by u/JustTryingToFunction: I won't hook up with guys with a "gay voice". Does this mean I'm a bad person?

Just asking because I've met up with a couple guys from Grindr and if I can tell they're gay from their voice I'll just turn around and leave. I'll just tell them "I'm not feeling it" and try not to let them know that's why I reject them and try to be pretty low key about it. Did you guys here feel this way and then change your mind? Or have you always liked either a masculine voice or a feminine voice? Or both?

- [deleted] There's a Netflix documentary about this called "Do I Sound Gay?" you might be interested in. For me it's less about "sounding gay" (whatever that means) and more about sounding like an annoying valley girl. I don't even care if you're feminine, it's just that particular cadence that gets on my nerves. 
- IsConstantlyLying Yes this. There are some gay dudes that talk girly and it does not bug me because it is not moronic. It is that dumbass way of talking that annoys the shit out of me. Even when girls do it. My only friend that is a girl had a period in her life where she talked like this and it drove me nuts.

So like everything she says sounds like a question? And like you just want to throttle them?

Even dudes with deep voices can talk like this.

- everyone-is-a-victim Kinda this actually. There's a guy who sits next to me in class and I knew pretty much right away he's gay because of the way he speaks, but it doesn't bother me. Probably because I can tell he's feminine, but it's not the annoying sounds like they're trying to sound that way voice.

- [deleted] thwts one boring doc.

- [deleted] To each their own, I personally found it funny how he tries to change his voice and fails hard at it.

- [deleted] Yep. No career in acting for him.

- Kai_Decadence I think you highlighted a very prominent thing in gay dating when it comes to fem guys. Whenever some guy mentions fem, they usually add more to it with things like catty, valley girl types. I'm a feminine gay guy and I don't talk like a valley girl or a "diva". I have met a fem guy who was the stereotype you're talking about but that was one out 3 other fem guys I've met. I can say with some clarity that the average feminine gay guy doesn't act like that.

- [deleted] I think it goes to show there are different ways to be feminine and masculine. I like masculine guys too but that doesn't mean I like obnoxious jocks and dudebros.

- Kai_Decadence Exactly. Both sides have their extreme versions. "HEY GIRL!" vs "HEY BRO!" lol

- aussie_guy1976 It's a great documentary and very enlightening

\section{[Topic 6, Excerpt \#3]}

Retrieved on 10/12/2018 from

https://www.reddit.com/r/ftm/comments/2n6c7v/how_to_not_talk_like_i_was_socialized_as_a_girl/

Posted on r/ftm by u/SidneyRush: How to not talk like I was socialized as a girl...

I don't mean pitch, I mean word choice, rhythm, what you stress, and all that other technical language stuff I slept through during speech class.

I'm having dysphoria surrounding my speech and writing. How did/do you guys pick up on male 
communication? I would like to come across as an adult male.

So far, I've got some general ideas:

1. speak slower

2. avoid fillers such as 'like' and 'just'

3. don't end your sentences with a rising pitch if they're not questions

4. guys don't pronounce things as sharply

5. use fewer emoticons and exclamaition points in text

6. guys have less emotional expression (but I don't want to sound like I'm stoned)

7. don't rely on 'I think' or 'I feel' or 'I believe' to soften a statement

8. grunting is a thing

- [deleted] I've heard cis guys who don't talk like this at all. Really, it's just the pitch you need. Sure, if you talk like a valley girl, you need to make some changes. But if you speak like everyone else, don't stress yourself out about it.

- mountainfold Not to be rude, but I know how I speak and putting it at a lower pitch will not magically make me sound like an expressive, effeminate man. It's awesome that a lower pitch is all some guys require to sound male. But I've spent years mimicking very feminine speech consciously and subconsciously in order to hide my sexuality and appease volatile family members.

I have a lot of valley girl I've rooted out already but I know I have more to improve on. This is important to me to work on.

- [deleted] ...Soooo like I said, unless you sound like a valley girl, it's not an issue. You just told me you sound like a valley girl, so thanks, I did not know that when I first commented. Keep working on it? Good luck? I don't know. You seem to already have everything down that you need to improve on.

- mountainfold Thanks.

- djf87 I don't know, I know a few cis gay men who speak completely "like women" in pretty much every way- word choice, inflection, rhythm, all of it, but they have male pitch. They sound like men- effeminate, expressive men, but men. No one would ever think they weren't men... I think the average person just probably assumes they are gay, or thinks nothing of it. I haven't ever heard of them being misgendered on the phone- if it happens I bet it's rare. I have heard a good amount of trans men (both gay and not) with feminine speech patterns. Once their voice lowers on T, if they retain that way of speaking, they sound like feminine, expressive men. I've never heard a trans man with a lowered voice who didn't sound male.

I respect that it's something you want to work on changing- that's obviously your choice. But if some of your patterns of speech remain, I wouldn't worry too much.

[Topic 6, Excerpt \#4] 
Retrieved on 10/12/2018 from

https://www.reddit.com/r/askgaybros/comments/5pje85/is_gayvoice_a_turn_on_to_anyone/

Posted in r/askgaybros by u/getthelumpout: Is "gay-voice" a turn on to anyone?

For some reason, some of us decided somewhere along the line that gay-voice was not masculine and/or we needed to change the way we talked to present ourselves as viable candidates.

For a while now, though, I've actually been seriously turned on with guys I'm attracted to having the quote-unquote "gay voice." I'm not talking about the overly dramatic, snapping, "yas queen," over the top voice (not that there's anything wrong with that. And that's mostly mannerism, anyway.) Just--when you hear a guy talk, and there's no question he's gay. There's something about it that goes right to my groin, like--you're a hot guy, and there's no mistaking that you like the $D$, and that's really sexy to me.

Part of me thinks there must be biological reason for it--it didn't develop for no reason whatsoever. Maybe it's a way that us like souls can identify each other (for safety, kinship, mating, whatever). All I know is, it's working.

- everyone-is-a-victim "For some reason, some of us decided somewhere along the line that gayvoice was not masculine"

wrong. It wasn't just some random coincidence. Women have much higher pitched voices than men, while men have much deeper voices. Though you can get some different variations of women's voices that are a little more rough or mens voices that are softer, but it's genetics. That's why trans people have to take certain meds so their voices change over as well.

"we needed to change the way we talked to present ourselves as viable candidates."

Just because someone doesn't like it doesn't mean you have to change, it means you should find someone who doesn't mind it.

"there must be biological reason for it-it didn't develop for no reason whatsoever"

Sure, genetics probably do play a part in it, but I think a large part is how someone grew up, or in other words their personality, which means it can't be helped. I had a guy in my class who obviously wasn't trying to sound or be feminine I could tell it was just his personality. While it may not have struck me as attractive, it didn't bother me.

- Andrew985 I have straight friends who have higher pitched or even feminine-sounding voices. Just sounding feminine is not enough to make it sound "stereotypically gay" to me anymore. If it's not dripping with flamboyance ("yas queen" may or may not be included) then it doesn't sound gay to me.

But I guess to answer your post question, no I do not find gay-voice attractive. Like most bros, I like guys who happen to be gay, not obviously gay guys.

[Topic 6, Excerpt \#5] 
Retrieved on 10/12/2018 from

https://www.reddit.com/r/askgaybros/comments/32itsk/is_the_stereotypical_gay_voice_an_instant_turnoff/

Posted on r/askgaybros by u/[deleted]: Is the stereotypical gay voice an instant turn-off for you?

I feel really shallow for thinking like this but I can't help it.

- $\quad$ startingover90 It's not an issue either way for me, I don't internalize homophobia.

- startingover 90 At the end of the day, if you both like cock, you are equally gay regardless of who's voice is more telling. I'd much rather fuck a guy who owns his feminine side/voice than one who is "straight acting" because he hates himself for being a big ol' queer.

- $\quad$ abrozzi Turn off, sexually? Definitely. It's not even with the fact that a stereotypical gay dude would have it, it's just the way they extended their words and how their voice goes up a few octaves.

- guyasking I think that may be me lol. My voice isnt a fem tone but I elongate some words and I don't even notice it until someone mocks my voice

○__Kannon I just hear my mother when i listen to it.

- samuelmouse I'm fine with it as long as it isn't at the point where his voice grates on my ears. I mean, some guys have naturally higher, more feminine voices, and I don't mind that. But when they go overboard with it it's not exactly attractive to me.

- vanisaac Not instant, but it can be a bit grating. Hopefully I can get something in his mouth to shut him up before I get too annoyed.

- Y6Y1Y9 Usually yes. It depends on how prominent it is. If it's pretty slight or not that noticeable. I can handle it. But when it's really super over the top and almost sounds like they are putting it on on purpose then i can handle it for about 5 minutes before i need to get away from the person. Nothing personal against those guys, it's just something that's always been annoying to me.

- loki8481 Honestly, it's a little bit of a turn-on for me. Love fucking an effeminate twink as he moans my name. 


\section{Appendix D: Subreddits Represented in Corpus}

Table A. 2

Subreddits Represented in Corpus and Total Number of Posts from Each

\begin{tabular}{|c|c|c|c|}
\hline$\#$ & Subreddit Title & \# of Posts (percentage) & \# of Posts (raw count) \\
\hline 1 & AskReddit & $19.8 \%$ & 15 \\
\hline 2 & askgaybros & $17.1 \%$ & 13 \\
\hline 3 & NoStupidQuestions & $10.5 \%$ & 8 \\
\hline 4 & gaybros & $9.2 \%$ & 7 \\
\hline 5 & explainlikeimfive & $6.6 \%$ & 5 \\
\hline 6 & linguistics & $6.6 \%$ & 5 \\
\hline 7 & gay & $3.9 \%$ & 3 \\
\hline 8 & answers & $2.7 \%$ & 2 \\
\hline 9 & $\mathrm{ftm}$ & $2.7 \%$ & 2 \\
\hline 10 & funny & $2.7 \%$ & 2 \\
\hline 11 & actuallesbians & $1.3 \%$ & 1 \\
\hline 12 & AskHistorians & $1.3 \%$ & 1 \\
\hline 13 & AskMen & $1.3 \%$ & 1 \\
\hline 14 & askscience & $1.3 \%$ & 1 \\
\hline 15 & AskSocialScience & $1.3 \%$ & 1 \\
\hline 16 & DotA2 & $1.3 \%$ & 1 \\
\hline 17 & ExplainLikeImHigh & $1.3 \%$ & 1 \\
\hline 18 & IWantToLearn & $1.3 \%$ & 1 \\
\hline 19 & JudgeMyAccent & $1.3 \%$ & 1 \\
\hline 20 & lgbt & $1.3 \%$ & 1 \\
\hline 21 & nba & $1.3 \%$ & 1 \\
\hline 22 & todayilearned & $1.3 \%$ & 1 \\
\hline 23 & TwoBestFriendsPlay & $1.3 \%$ & 1 \\
\hline \multirow[t]{2}{*}{24} & videos & $1.3 \%$ & 1 \\
\hline & Total & $100 \%$ & 76 \\
\hline
\end{tabular}

